DOI: $10.2478 / \mathrm{v} .10169-012-0016-\mathrm{x}$

\title{
ESTIMATION OF STIFFNESS AND ENERGY DISSIPATION FOR THE MODELS OF REINFORCED-CONCRETE COMPOSITE SLABS BASED ON THE INVESTIGATIONS OF STATICALLY LOADED SLABS
}

\author{
K. GROMYSZ ${ }^{1}$
}

\begin{abstract}
Reinforced concrete composite slab consists of a thin prefabricated slab in which span reinforcement is located and of concrete joined with the slab, with such concrete being laid on site.

The existence of a joint of two concretes in such floors is interpreted as introducing a contact layer into a monolithic slab. In the paper parameters of two models are estimated. The first is a model of a contact layer and the second is a model of a composite slab with a single degree of freedom. The models consider that the contact has elastic properties and inelastic properties causing energy dissipation. Experimental investigations are discussed further based on which the parameters values of the contact layer model were determined.

Delamination was experienced for the slabs characterised by low contact layer stiffness after applying a maximum load. In addition, the strains of a contact layer having low stiffness are accompanied by lower energy dissipation than of a layer with high stiffness.

The smaller stiffness of composite floors, as compared to monolithic floors, occurs as a consequence of the existence of a joint. Such decrease for a composite slab is interpreted in the model with a single degree of freedom as the serial connection of stiffness of a monolithic slab and an element considering the existence of a contact layer.

The stiffness of an element considering the existence of a contact layer decreases along with a load, and the elements corresponding to the higher stiffness of the contact layer are characterised by higher energy dissipation.

The aforementioned results of the investigations confirm the assumptions of the contact layer model and a composite slab model with a single degree of freedom. The findings made represent a basis for establishing a method of evaluating the condition of a joint in composite slabs according to statistical investigations.
\end{abstract}

Key words: reinforced concrete, composite slab, hysteresis loop, energy dissipation.

\section{INTRODUCTION}

Reinforced-concrete composite slabs consist of two concrete layers: a thin prefabricated slab in which span reinforcement is located and of the concrete joint being laid on site [1]. Decisive for the load capacity of freely supported composite slabs is mainly the

\footnotetext{
${ }^{1}$ Silesian University of Technology, Department of Building Structures, ul. Akademicka 5, 44-100 Gliwice, krzysztof.gromysz@polsl.pl
} 
ability to transmit horizontal shear forces by a joint of two layers of concrete [2]. The purpose of the paper is to estimate the parameters of the two models: a model of a joint and the parameters of a composite slab with a single degree of freedom. In order to assess the joint's ability to transmit longitudinal shear forces in composite slabs, it is fundamental to know the values of such parameters.

The article mentions a model of joint of a prefabricated element with concrete laid on site in a single-span slab established in [3] and a model of a reinforced-concrete composite slab with a single degree of freedom described in [4]. The laboratory tests of six single-span slabs are next described, i.e. of five dual-layer slabs and of one monolithic slab. The results of such slabs' tests are a basis for estimating the parameters of the models.

\section{Key PARAMETERS OF THE MODELS}

A model of a reinforced-concrete composite slab assumes [3] [4], that the slab is made up of three layers: a bottom layer represented by a prefabricated element, a top layer represented by concrete laid on site and a contact layer (Fig. 1a). In this model, a contact layer is assigned the characteristics reflecting the phenomena occurring in a joint of a prefabricated slab with concrete laid on site.

\subsection{BASIC NOtations}

Provided below are the most important notations referring to the stiffness and energy dissipation parameters in the model of contact layer, model of composite concrete floor [4] and parameters determined experimentally:

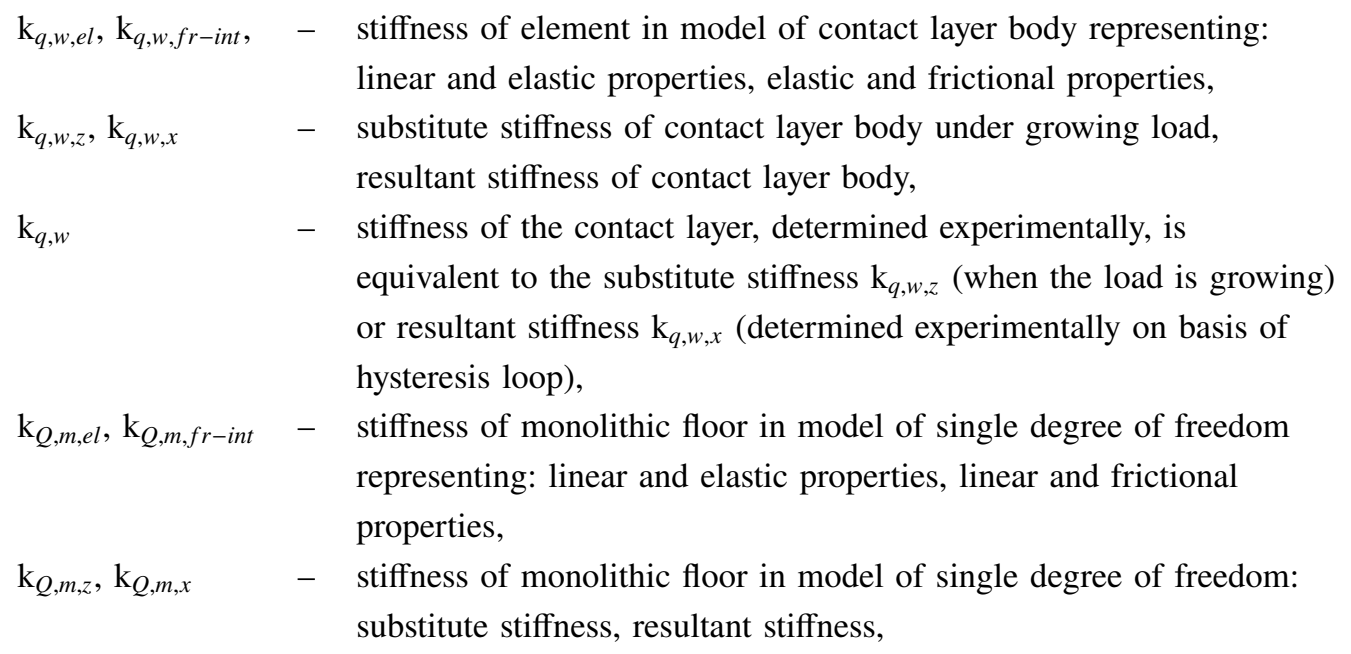




\begin{tabular}{|c|c|c|}
\hline $\mathrm{k}_{Q, m}$ & - & $\begin{array}{l}\text { stiffness of the monolithic concrete floor at the point*, determined } \\
\text { experimentally on basis of hysteresis loop is equivalent to the resul- } \\
\text { tant stiffness } \mathrm{k}_{Q, m, x} \text {, }\end{array}$ \\
\hline $\mathrm{k}_{Q, w, e l}, \mathrm{k}_{Q, w, f r-i n t}$ & - & $\begin{array}{l}\text { component stiffness of composite concrete floor in model of single } \\
\text { degree of freedom modelling: linear and elastic properties, linear } \\
\text { and frictional properties, }\end{array}$ \\
\hline $\mathrm{k}_{Q, w, z}, \mathrm{k}_{Q, w, x}$ & - & $\begin{array}{l}\text { stiffness in model of single degree of freedom of composite concrete } \\
\text { floor: component of substitute stiffness, component of resultant } \\
\text { stiffness, }\end{array}$ \\
\hline $\mathrm{k}_{Q, w}$ & - & component stiffness of composite concrete floor at the point*, \\
\hline $\mathrm{k}_{Q, w, m, x}$ & - & $\begin{array}{l}\text { resultant stiffness of the composite concrete floor model of single } \\
\text { degree of freedom, }\end{array}$ \\
\hline $\mathrm{k}_{Q, w, m}$ & - & $\begin{array}{l}\text { stiffness of composite concrete floor at the point*; determined experi- } \\
\text { mentally on basis of hysteresis loop is equivalent to resultant stiffness } \\
\mathrm{k}_{Q, w, m, x} \text {, }\end{array}$ \\
\hline$\chi_{Q, m}, \chi_{Q, w, m}$ & - & $\begin{array}{l}\text { energy absorption coefficient determined experimentally or in model } \\
\text { of: monolithic concrete slab, composite concrete slab, }\end{array}$ \\
\hline$\psi_{Q, m}, \psi_{Q, w, m}$ & - & $\begin{array}{l}\text { hysteresis loop area determined experimentally or in model of: mono- } \\
\text { lithic concrete slab, composite concrete slab, }\end{array}$ \\
\hline $\mathrm{V}_{Q, m}, \mathrm{~V}_{Q, w, m}$ & - & $\begin{array}{l}\text { the smallest area of rectangle into which the loops of area } \psi_{Q, m} \text { and } \\
\psi_{Q, w, m} \text { can be inscribed. }\end{array}$ \\
\hline
\end{tabular}

* The point is meant as a point in the middle of the slab's span where the force Q is applied.

The parameters to be determined experimentally during the tests carried out on composite and monolithic floors are: $\mathrm{k}_{q, w}, \mathrm{k}_{Q, m}, \mathrm{k}_{Q, w, m}, \chi_{Q, m}, \chi_{Q, w, m}$. The value of other parameters can be determined based on the parameter values identified in the tests.

\subsection{Contact layer model}

A mechanical model of a body describing a contact layer is represented by the serial connection of a linear-elastic element and an elastic-frictional element (Fig. 1b). The linear-elastic element is characterised by the stiffness $\mathrm{k}_{q, w, e l}$. The elastic-frictional element under the growing load is characterised by the stiffness $\mathrm{k}_{q, w, f r-i n t}$, but does not exhibit any deformations under the decreasing load.

A body describing a contact layer under a growing load, as the serial connection of two stiffnesses, is characterised by the following substitute stiffness

$$
k_{q, w, z}=\frac{k_{q, w, e l} \cdot k_{q, w, f r-i n t}}{k_{q, w, e l}+k_{q, w, f r-i n t}},
$$


a)

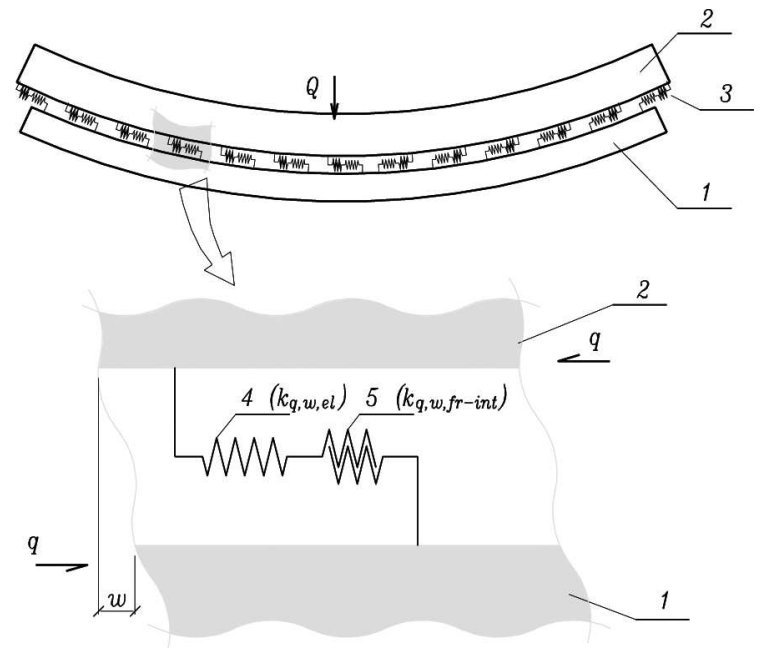

Fig. 1. Reinforced-concrete composite slab a) slab model b) a model of a body describing a contact layer 1 - bottom layer, 2 - top layer, 3 - contact layer, 4 - element in a model of a contact layer body representing linear - elastic properties, 5 - element in a model of a contact layer body representing elastic - frictional properties.

and under a decreasing load, by the stiffness $\mathrm{k}_{q, w, e l}$. A hysteresis loop is created in the cycle of loading and unloading with its diagonal representing the resultant stiffness $\mathrm{k}_{q, w, x}$ (Fig. 2a).

The distribution of horizontal displacements of the bottom layer relative to the top layer caused by the deformations of the contact layer under the growing load in a freely supported slab loaded with a concentrated force (Fig. 2b) is described by a harmonic function [3]

$$
w_{e l}(x)=\frac{3 q}{k_{q, w, z}}\left\{\sin \left[\sqrt{\frac{k_{q, w, z}}{b E_{c} h_{g}}}\left(\frac{l}{2}-x\right)\right]\right\}^{2},
$$

with its amplitude of $3 \mathrm{q} / \mathrm{k}_{q, w, z}$. In the equation (2.2), $b$ signifies slab width, $q$ signifies horizontal shear force determined as the quotient $V / z$, where $V$ is vertical force, $z$ - an arm of internal forces of the reinforced-concrete section being bent, $E_{c}$ - the elasticity modulus of the top and bottom layer, $h_{g}$ - height of the top layer, $l-\operatorname{span}, x-\mathrm{a}$ coordinate according to Fig. 2b. Fig. 2c shows the distribution of displacements for the top layer relative to the bottom layer for the different stiffnesses $\mathrm{k}_{q, w, z}$.

In contrast to the models of elastic plastic materials [5], in which the hysteresis loop is formed after the exhaustion elastic range, the material model adopted takes into account the presence of permanent deformation at low loads. 
a)

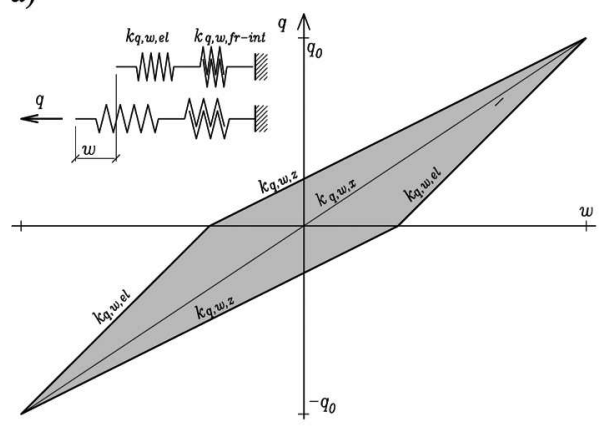

b)

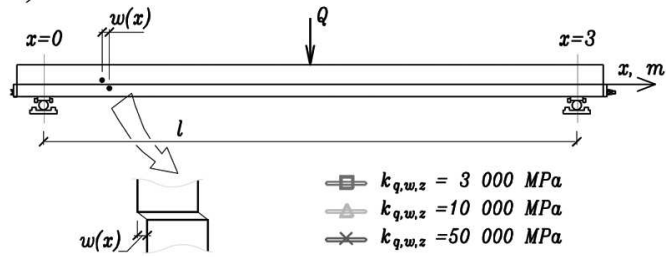

c)

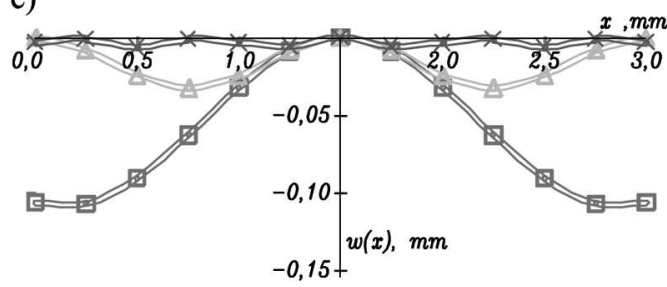

Fig. 2. Properties of the contact layer model a) hysteresis loop of a body describing a contact layer b) freely supported composite slab c) distribution of horizontal displacements of the bottom layer relative to the top layer in a freely supported slab.

\subsection{Model of COMposite Slab With a Single DegReE OF FREEDoM}

A model of a reinforced-concrete composite slab with a single degree of freedom combines a model of a monolithic slab with a single degree of freedom and an element describing the influence of the contact layer.

A model of a monolithic slab is represented by the parallel connection of a linear elastic element characterised by the stiffness $\mathrm{k}_{Q, m, e l}$ and of an elastic - frictional element describing internal friction. The elastic - frictional element, under the growing load, is characterised by the stiffness $\mathrm{k}_{Q, m, f r-i n t}$, and it does not exhibit any displacements under a decreasing load. The monolithic slab model, in a full loading and unloading cycle, generates a hysteresis loop with the area of $\psi_{Q, m}$ and is featuring the resultant stiffness $\mathrm{k}_{Q, m, x}$ (Fig. 3a). A hysteresis loop of the monolithic slab model can be inscribed into a rectangle with the area of

$$
V_{Q, m}=\Delta Q \cdot \Delta y,
$$

where $\Delta \mathrm{Q}$ is a variation of the loading force and $\Delta \mathrm{y}$ is displacement caused by such a variation (Fig. 3a). The quotient

$$
\chi_{Q, m}=\frac{\psi_{Q, m}}{V_{Q, m}}
$$

is an energy dissipation coefficient of the monolithic slab model.

An element describing the influence of the contact layer, by reference to the model of a body describing the contact layer, consists of the serial connection of the 
a)

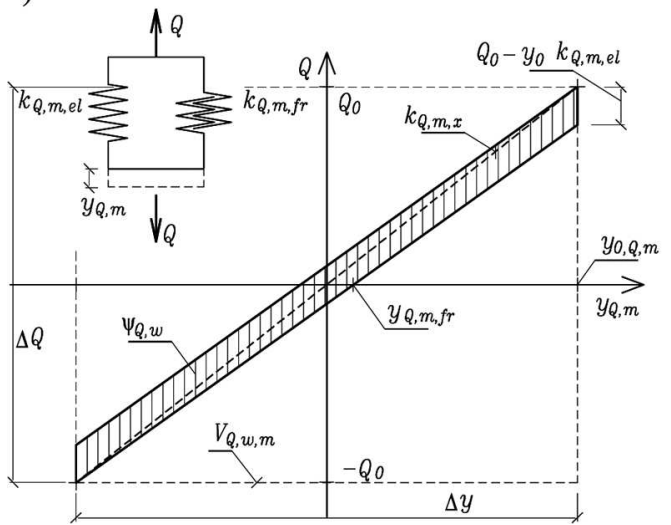

b)

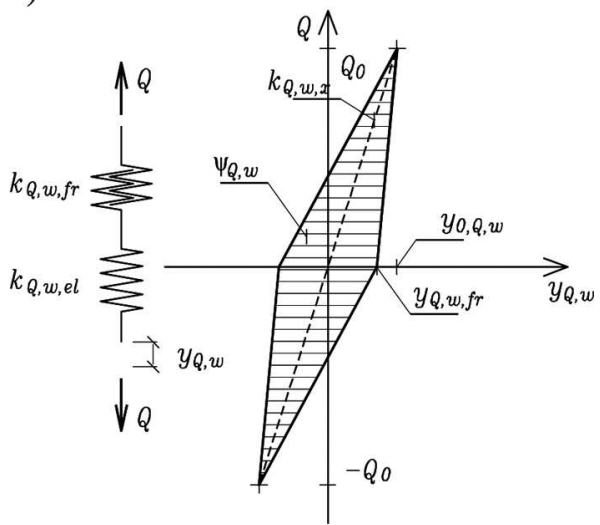

Fig. 3. Elements of the composite slab model with a single degree of freedom a) an element modelling a monolithic slab and hysteresis loop of an element, b) an element describing the influence of a contact layer and a hysteresis loop of the element.

linear-elastic element with the stiffness $\mathrm{k}_{Q, w, e l}$ and of an elastic-frictional element. The stiffness elastic-frictional element under the growing load is $\mathrm{k}_{Q, w, f r-i n t}$, and does not exhibit displacements under the decreasing load (Fig. 3b). The area of a hysteresis loop of the element describing the influence of the contact layer equals $\psi_{Q, w}$, and a diagonal of the rhomb describing the hysteresis of this element corresponds to the stiffness $\mathrm{k}_{Q, w, x}$ (Fig. 3b).

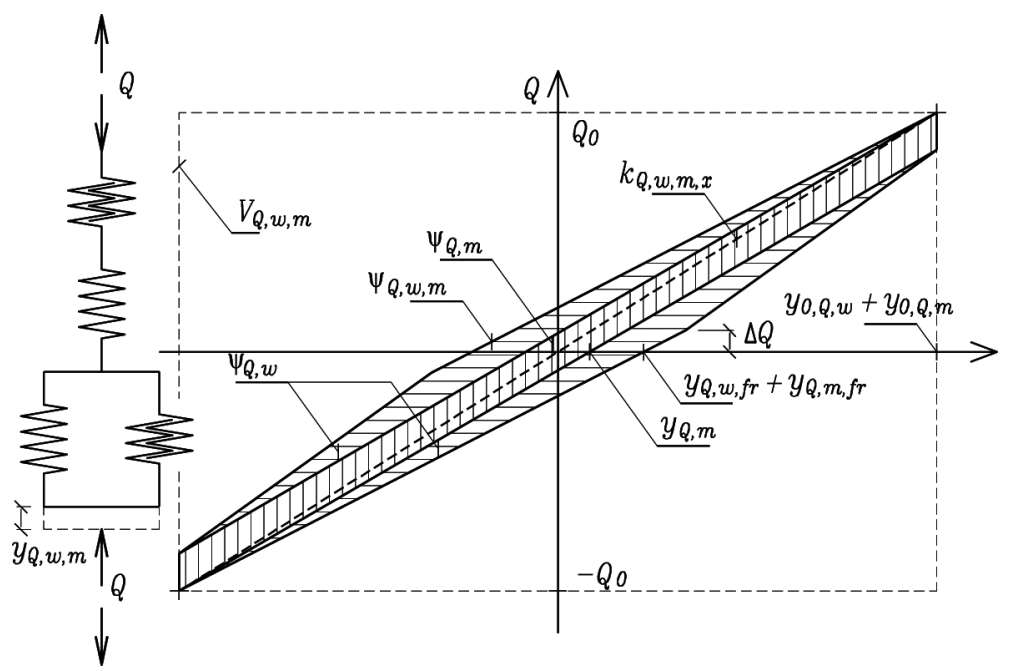

Fig. 4. Model with a single degree of freedom of the reinforced-concrete composite slab and hysteresis loop caused by cyclic load 
A model of a reinforced-concrete composite slab with a single degree of freedom combining a model of a monolithic slab and an element describing the influence of the contact layer (Fig. 4) in a full loading and unloading cycle is characterised by the area of the hysteresis loop of

$$
\psi_{Q, w, m}=\psi_{Q, w}+\psi_{Q, m}
$$

The area can be inscribed into a rectangle with the area of $\mathrm{V}_{Q, w, m}$ and an energy dissipation coefficient of the composite slab model can be determined

$$
\chi_{Q, w, m}=\frac{\psi_{Q, w, m}}{V_{Q, w, m}},
$$

where $\mathrm{V}_{Q, w, m}$ is the area of the rectangle into which a loop was inscribed with the area of $\psi_{Q, w, m}$. An energy dissipation coefficient in the element describing the influence of the contact layer $\chi_{Q, w}$, by assuming that $\mathrm{k}_{Q, w, x}>>\mathrm{k}_{Q, m, x}$, is determined as follows

$$
\chi_{Q, w}=\chi_{Q, w, m}-\chi_{Q, m} .
$$

The diagonal of a figure with the area of $\psi_{Q, w, m}$ corresponds to the resultant stiffness of the composite slab model and is (Fig. 4)

$$
k_{Q, w, m, x}=\frac{k_{Q, w, x} \cdot k_{Q, m, x}}{k_{Q, w, x}+k_{Q, m, x}} .
$$

\subsection{Numerical MOdel OF COMPOSITE SLAB}

The calculations of a linear and elastic MES model were performed in [4] using disc elements, of a composite slab consisting of the three layers: the bottom layer with the height of $\mathrm{h}_{d}=0.07 \mathrm{~m}$, the top layer with the height of $\mathrm{h}_{g}=0.11 \mathrm{~m}$ and the contact layer with the stiffness $\mathrm{k}_{q, w}$.

Slab stiffness in the point of application of force $\left(\mathrm{k}_{Q, w, m}\right)$ was obtained as a result of calculations for the model of a single-span, freely supported composite slab loaded in the centre of the span with the force Q (Fig. 5a), as the following quotient:

$$
k_{Q, w, m}=\frac{Q}{y_{Q, w, m}}
$$

where $\mathrm{y}_{Q, w, m}$ signifies the deflection of the composite slab in the point of application of force Q.

The stiffness of a composite slab in the point $\left(\mathrm{k}_{Q, w, m}\right)$ was decreasing as the stiffness of the contact layer $\left(\mathrm{k}_{q, w}\right)$ was decreasing. As a result of the same calculations for a 
monolithic slab with the height $\mathrm{h}=0.18 \mathrm{~m}$, its stiffness in the point of application of force $\mathrm{Q} \mathrm{k}_{Q, m}$ was obtained as the following quotient

$$
k_{Q, m}=\frac{Q}{y_{Q, m}},
$$

where $\mathrm{y}_{Q, m}$ signifies the deflection of a monolithic slab in the point of application of force Q.

a)

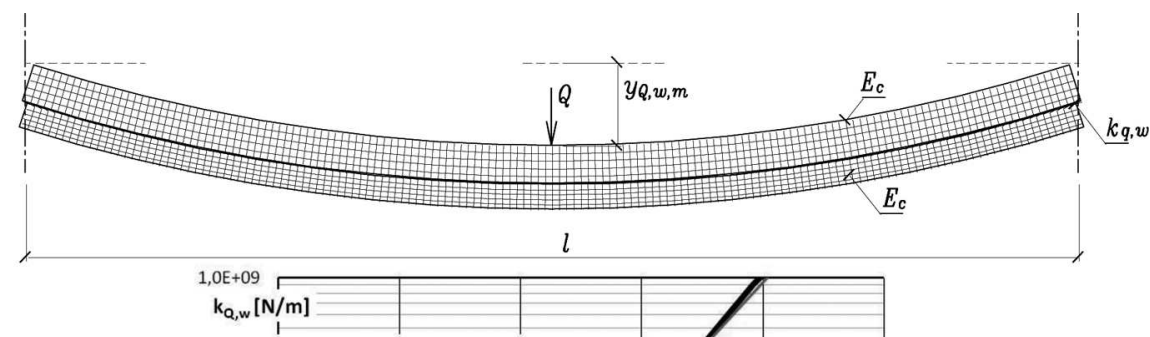

b)

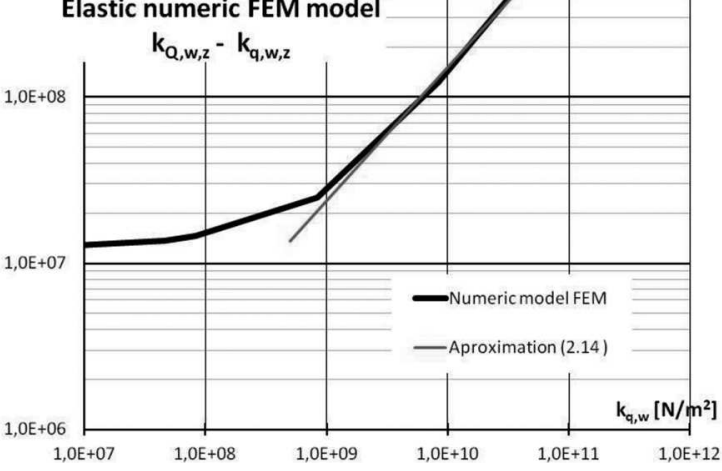

Fig. 5. A MES numerical model of a composite slab a) model parameters, b) the relationship obtained between $\mathrm{k}_{Q, w}$ and $\mathrm{k}_{q, w}$ and the approximation of this relationship according to (2.14) within the stiffness range $\mathrm{k}_{q, w}$ of $5 \cdot 10^{8} \mathrm{~N} / \mathrm{m}^{2}$ to $5 \cdot 10^{11} \mathrm{~N} / \mathrm{m}^{2}$.

The stiffness of the element describing the influence of the contact layer $\mathrm{k}_{Q, w}$ was determined according to the following equation

$$
y_{Q, w, m}=y_{Q, m}+y_{Q, w}
$$

and the relationships (2.9) and (2.10) as

$$
k_{Q, w}=\frac{k_{Q, m}-k_{Q, w, m}}{k_{Q, m} \cdot k_{Q, w, m}} .
$$

The relationship between the stiffness of the contact layer $\left(\mathrm{k}_{q, w}\right)$ and the stiffness of the element describing the influence of the contact layer $\left(\mathrm{k}_{Q, w}\right)$, for the bottom and 
top layer material characterised by the modulus $\mathrm{E}_{c}=40 \mathrm{GPa}$, is shown in Fig. $5 \mathrm{~b}$. It was noted that the relationship between $\mathrm{k}_{q, w}$ and $\mathrm{k}_{Q, w}$, within the stiffness range $\mathrm{k}_{q, w}$ of $5 \cdot 10^{8} \mathrm{~N} / \mathrm{m}^{2}$ to $5 \cdot 10^{11} \mathrm{~N} / \mathrm{m}^{2}$ for the considered model of slabs can be interpolated with an exponential function (Fig. 5b).

$$
k_{Q, w}=1.5 \cdot\left(k_{q, w}\right)^{0.8} .
$$

\section{RESEARCH PROGRAMME}

The purpose of the research was the estimation of the parameters of a contact layer model and a composite slab model. The research was designed in such a way as to determine contact layer stiffness $\left(\mathrm{k}_{q, w}\right)$, composite slab stiffness in the point of application of force $\mathrm{Q}\left(\mathrm{k}_{Q, w, m}\right)$, monolithic slab stiffness in the point of application of force $\mathrm{Q}\left(\mathrm{k}_{Q, m}\right)$ and the component stiffness of the slab describing the influence of the contact layer $\left(\mathrm{k}_{Q, w}\right)$. In addition, energy dissipation coefficients for composite slabs $\left(\chi_{Q, w, m}\right)$ and a monolithic slab $\left(\chi_{Q, m}\right)$ were determined during the research.

\subsection{RESEARCH ELEMENTS}

The research was made for six freely supported slabs, each $3300 \mathrm{~mm}$ long, $\mathrm{b}=590 \mathrm{~mm}$ wide, $\mathrm{h}=180 \mathrm{~mm}$ high with the span length of $1=3000 \mathrm{~mm}$. The following five slabs, i.e. P1, P3, P4, P5, P6 were composite slabs, and one, P2, was a monolithic slab. The height of the composite slabs' top layer $\left(\mathrm{h}_{g}\right)$ was $110 \mathrm{~mm}$ and the bottom $\left(\mathrm{h}_{d}\right) 70 \mathrm{~mm}$.

Span reinforcement of each slab consisted of six ribbed bars with the diameter of $20 \mathrm{~mm}$, the axis of which was $30 \mathrm{~mm}$ away from the bottom layer of the slabs. Vertical reinforcement in form of two trusses made of smooth bars with the diameter of $6 \mathrm{~mm}$ welded to a bar with the diameter of $20 \mathrm{~mm}$ was used for five slabs, i.e. P1, P2, P3, P4, P6 (Fig. 6a).

Four types of the joint surface were made for the composite slabs (Fig. 6b): a smooth surface - levelled with a trowel (P1, P6), a smooth surface made using a mould made of shuttering plywood (P3), with $5 / 5 \mathrm{~mm}$ indentations every $50 \mathrm{~mm}$ made as a mould cast made of shuttering plywood (P5) and with adhesion removed at the entire width of the cross section (P4) and with adhesion removed at the partial width of the cross section (P6).

The width of the joint was the same as the width of the slabs and was limited in one case to $200 \mathrm{~mm}$ (P6 slab).

\subsection{Phases OF LOADING}

The extensive research programme of the slabs was designed covering ten phases of loading, marked, respectively, with numbers between 1 to 10 (Table 1). Two types of 
a)

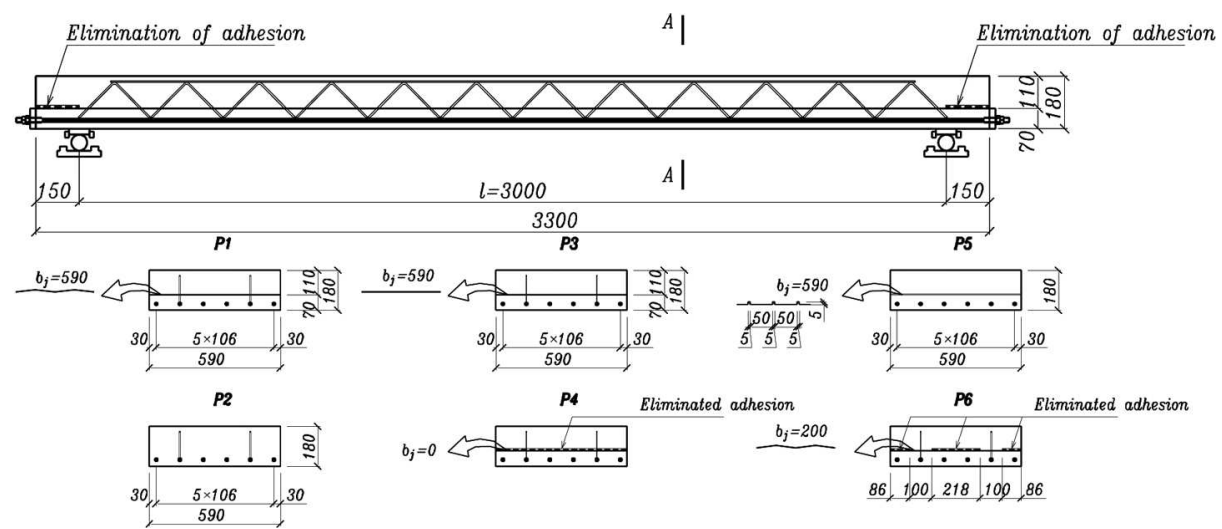

Fig. 6. The research elements a) longitudinal section through the slab, b) cross section through the slab.

loading were distinguished between during the phases, i.e. cyclic loading (phases 1, 2, 3,4 and $7,8,9,10$ ) and monotonic loading with controlled unloading (phases 5, 6). Irrespective of the loading phase and type, the slabs were loaded with the concentrated force $\mathrm{Q}$ applied in the middle of the span and acting in a vertical direction.

Table 1

Loading phases.

\begin{tabular}{|c|l|l|l|}
\hline $\begin{array}{c}\text { Loading } \\
\text { phase }\end{array}$ & Load type & $\begin{array}{c}\text { Slab } \\
\text { condition }\end{array}$ & Load description \\
\hline 1 & Cyclic loading & "0" & $\begin{array}{l}\text { Forcing the displacement of the slab at the centre } \\
\text { of the span (y - in the point) over the range of } \\
-0.1 \mathrm{~mm} \text { to } 0.1 \mathrm{~mm}(\mathrm{~A}=0.1 \mathrm{~mm})\end{array}$ \\
\hline 2 & Cyclic loading & "0" & As above, A = 0.5 mm \\
\hline 3 & Cyclic loading & "0" & As above, A = $1 \mathrm{~mm}$ \\
\hline 4 & Cyclic loading & "0" & As above, A = 2 mm \\
\hline 5 & $\begin{array}{l}\text { Monotonic loading } \\
\text { with controlled unloading }\end{array}$ & "I" & $\begin{array}{l}\text { Loading the slab with the force Q at the centre of } \\
\text { the span with the value rising from 0 to Q } \\
\text { unloading to 0 }\end{array}$ \\
\hline 6 & $\begin{array}{l}\text { Monotonic loading } \\
\text { with controlled unloading }\end{array}$ & "II" & $\begin{array}{l}\text { Loading the slab with the force Q at the centre } \\
\text { of the span with the value rising from 0 to Q } \\
\text { unloading to 0 }\end{array}$ \\
\hline 7 & Cyclic loading & "II" & $\begin{array}{l}\text { Forcing the displacement of the slab at the centre } \\
\text { of the span }(\mathrm{y}-\text { in the point) over the range of } \\
-0.1 \mathrm{~mm} \text { do } 0.1 \mathrm{~mm}(\mathrm{~A}=0.1 \mathrm{~mm})\end{array}$ \\
\hline 8 & Cyclic loading & "II" & As above, A = 0.5 mm \\
\hline 9 & Cyclic loading & "II" & As above, A = $1 \mathrm{~mm}$ \\
\hline 10 & Cyclic loading & "II" & As above, A = $2 \mathrm{~mm}$ \\
\hline
\end{tabular}

Cyclic loads consisted in applying a small load to the slab several times alternately with the negative sense - when the force Q was directed downwards - and with the 
positive sense - when the force Q was directed upwards. Slab deflection at the centre of the span was forced this way (slab deflection in the point) within the range of $-\mathrm{A}$ to A. The value A called amplitude was assuming the following values in the subsequent phases: $0.1 \mathrm{~mm}, 0.5 \mathrm{~mm}, 1 \mathrm{~mm}$ and $2 \mathrm{~mm}$.

Monotonic loading with controlled unloading consisted in loading the slab with the substantial force Q directed downwards and then in unloading the slab. The condition of the slabs after loading with monotonic force were changing as cracks were occurring caused by bending moments or as the bottom layer was displacing relative to the top layer.

Three conditions of the slabs were differentiated. The condition "0" was assumed to be a condition prior to commencing monotonic loading, i.e. a condition while performing cyclic loads for phases $1,2,3,4$. The condition "I" was marked as the slab condition obtained during the 5th phase of loading, i.e. after applying a force designated as $\mathrm{Q}_{I}$ to the slab. Efforts were made that the value of the load $\mathrm{Q}_{I}$ corresponds approximately to a half of the maximum load, designated as $\mathrm{Q}_{I I}$ and was applied in the 6th phase of loading. The condition of the slab after applying the maximum load was designated as the "II" condition. The cyclic loads of phases 7, 8, 9 and 10 were, therefore, applied to the slabs in the "II" condition.

\subsection{The values Measured}

The following values were measured when testing the slabs: the loading force $(\mathrm{Q}-$ Fig. 7a), the deflection of an element at the centre of the span $(y-$ Fig. 7a), relative horizontal displacements of the top layer in relation to the bottom layer $\left(\mathrm{w}_{i p}, \mathrm{w}_{1}, \mathrm{w}_{i l}\right.$, $\mathrm{i}=2 \ldots 7$ - Fig. $7 \mathrm{~b}$ ), the strains of the side surfaces of the vertical reinforcement bars according to which the following forces were determined: $\mathrm{F}_{p i l}, \mathrm{~F}_{p i p}, \mathrm{i}=2 \ldots 6$ (Fig. 7c) as well as the strains of span reinforcement at the centre of the span, according to which the force $\mathrm{F}_{s}$ in such reinforcement was determined. The indices in the designations of measurements of layers displacement and forces in vertical reinforcement contain information about the symmetric side of the loaded slab and the index " $p$ "signifies the right side and " $l$ " the left side. Besides, supplementary investigations were planned for concrete and steel.

\section{Results of THE RESEARCH}

The deflections and displacements were recorded by means of equipment ensuring the graininess of the displacements measured of $0.001 \mathrm{~mm}$. The graininess resulted from the parameters of an analogue-to-digital converter, not from the accuracy of readings of the induction sensors. The maximum measured displacement value was $20 \mathrm{~mm}$. Hence, the range of the displacements presented at the individual phases of loads varies between $0.001 \mathrm{~mm}$ to $20 \mathrm{~mm}$. 
a)

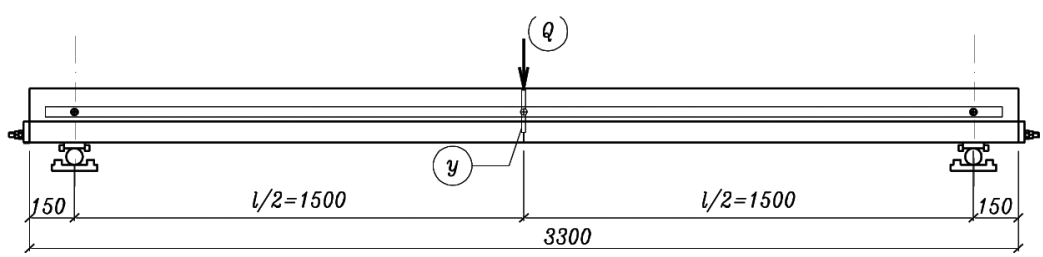

b)

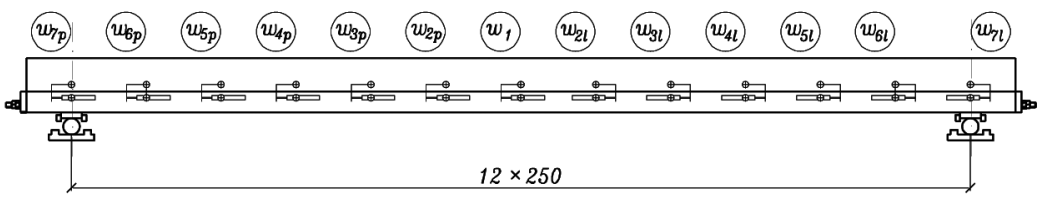

c)

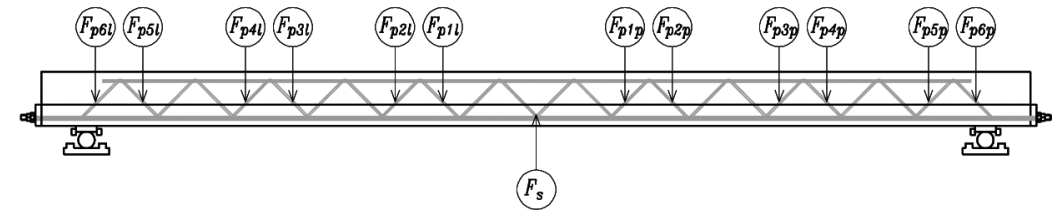

Fig. 7. The measurements performed during the tests a) measurement of vertical displacement of the slab (y) in the point of application of force Q, b) measurement of displacements of the bottom layer in relation to the top layer, c) measurement of strains of vertical and span reinforcement.

\subsection{Slabs SUbJected to monotonic LOADS With CONTROLLED UNLOAdiNG}

All the slabs under the load $\mathrm{Q}_{I I}$ reached substantial deflections or their load capacity was coming to an end, whereas in the case of the slabs P1, P4 and P6, delamination occurred after applying the force $\mathrm{Q}_{I I}$. The values of the forces $\mathrm{Q}_{I}$ and $\mathrm{Q}_{I I}$ and of the deflection $\mathrm{y}_{I}$, corresponding to the force $\mathrm{Q}_{I}$, are listed in Table 2. Deflections under the load $\mathrm{Q}_{I I}$ were not given as the measurement of displacements with the substantial deflections of elements could not have been made.

Table 2

The determined values of the loading force $\mathrm{Q}_{I}$ and those caused by this deflection force and the maximum force $\mathrm{Q}_{I I}$ loading the slab.

\begin{tabular}{|c|r|r|r|}
\hline \multirow{2}{*}{ Element } & $\mathrm{Q}_{I}$ & $\mathrm{y}_{I}$ & $\mathrm{Q}_{I I}$ \\
\cline { 2 - 4 } & {$[\mathrm{kN}]$} & {$[\mathrm{mm}]$} & {$[\mathrm{kN}]$} \\
\hline P1 & 120.410 & 11.988 & 165 \\
\hline P2 & 139.971 & 13.434 & 265 \\
\hline P3 & 75.269 & 7.625 & 260 \\
\hline P4 & 31.008 & 9.618 & 45 \\
\hline P5 & 131.290 & 17.808 & 270 \\
\hline P6 & 46.947 & 17.411 & 74 \\
\hline
\end{tabular}


4.1.1. Horizontal displacements in the joint

Fig. 8 shows charts illustrating the distribution of horizontal displacements of the top layer in relation to the bottom layer in dual-composite slabs loaded with the forces $\mathrm{Q}_{I}$ in the 5th stage of loading. The values marked with points were measured with sensors and the continuous lines only interpolate, in a linear manner, the distribution of displacements between the points. A sensor showing the highest displacement values is highlighted in the charts for each slab.

Fig. 9 shows the recorded displacements of the sensors $\mathrm{w}_{i p}$ in the 5 th phase of loading, i.e. with loading rising from 0 to the value $\mathrm{Q}_{I}$ and lowering again do zero.

a)

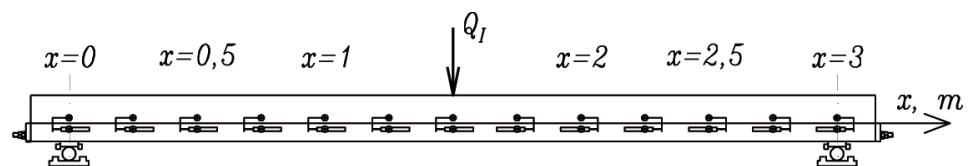

b)

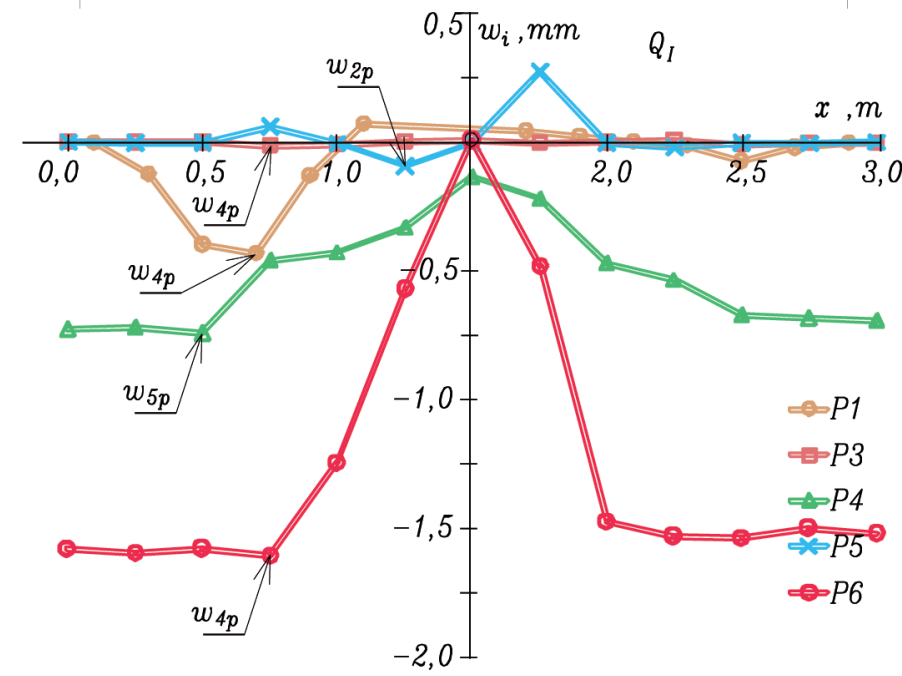

Fig. 8. The results of measurement of horizontal displacement of the bottom layer in relation to the top layer recorded in the 5th phase of loading under loading with the force $\mathrm{Q}_{I}$ a) measurement diagram,

b) distribution of displacements.

It can be concluded by analysing the progress of the presented relationships $\mathrm{w}_{i p}(\mathrm{Q})$ $(i=1, . .5)$ that, in the case of all the slabs, they are characterised by the occurrence of hysteresis loops, i.e. the loading line does not coincide with the unloading line, and that permanent displacements remain in the joint after unloading. It was also noted that, all the sensors showed displacements almost from the very beginning of loading. All the lines $\mathrm{w}_{i p}(\mathrm{Q})$ within the range of displacements of 0 to approx. $0.1 \mathrm{~mm}$ are similar to straight lines. This finding confirms an assumption made in the contact layer model providing that a proportion between elastic strains and inelastic strains is constant at small displacements with the rising load. 
a)

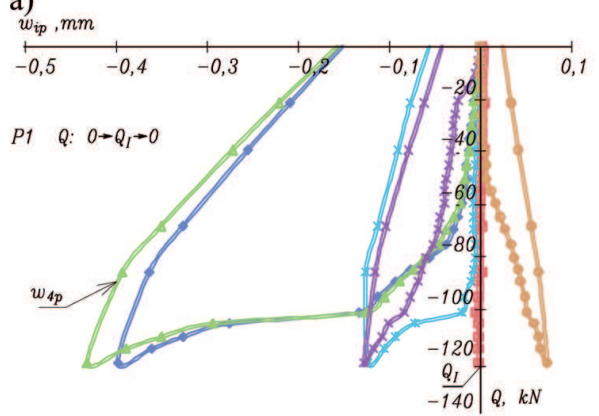

c)

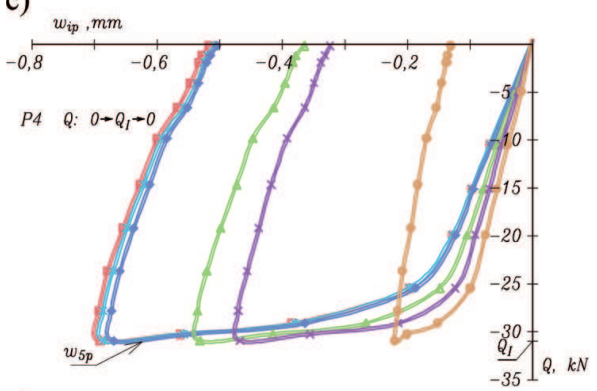

e)

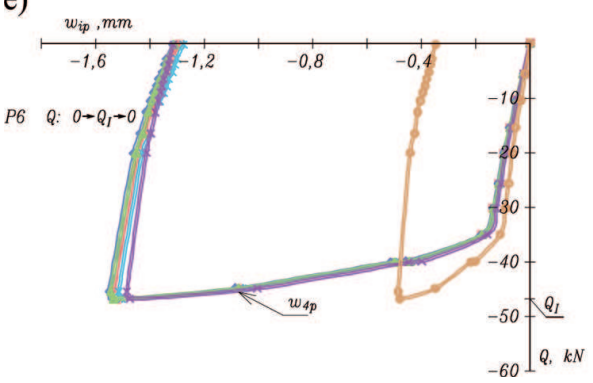

b)

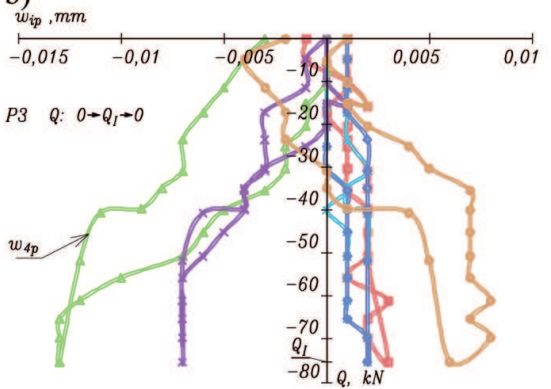

d)

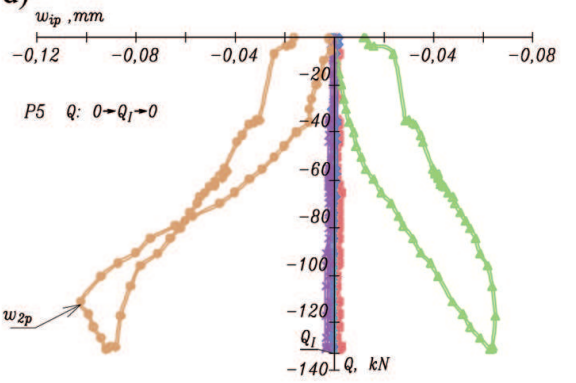

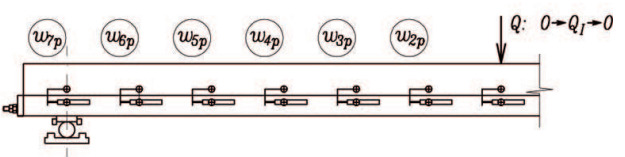

Fig. 9. Displacements of the bottom layer in relation to the top layer in dual-layer slabs recorded by the sensors $\mathrm{w}_{i p}$ in the 5th phase of loading (loading from 0 to the force $\mathrm{Q}_{I}$ and unloading to 0 )

The shape of the loops obtained can be assigned to one of two groups. The first group encompasses the curves corresponding to the P3 and P5 slabs, in which the line $\mathrm{w}(\mathrm{Q})$, corresponding to loading and unloading, has a curve similar to parallel lines. Hysteresis in this group of curves $w(Q)$ results from the progress of strains in the first phase of slabs unloading when a decrease in the value of the loading force $\mathrm{Q}$ does not change the displacement of the top layer in relation to the bottom layer.

The other group of curves $\mathrm{w}(\mathrm{Q})$ is represented by curves corresponding to the slabs P1, P4 and P6. The loading process in this group consists of two sections. The first section, where the line $\mathrm{w}(\mathrm{Q})$ corresponding to the loading process is inclined under a large angle to the horizontal axis, and the second section, where the line is 
inclined under a small angle to the horizontal line. The slab w(Q) inclination angle changes when the displacement of the bottom layer relative to the top layer reaches a displacement value of approx. $0.1 \mathrm{~mm}$. The section of the line $\mathrm{w}(\mathrm{Q})$ corresponding to unloading is running parallel to the first section of the loading process.

The above findings allow to conclude that neither the joint type nor the loading value decide whether the curve $\mathrm{w}(\mathrm{Q})$ belongs to a particular group. The decisive parameter here is the displacement value. If maximum displacement is smaller than approx. $0.1 \mathrm{~mm}$, then this curve belongs to a group represented by curves corresponding to the slab P3 (Fig. 9b) and if higher than approx. $0.1 \mathrm{~mm}$, then this curve belongs to a group represented by curves corresponding to the slab P6 (Fig. 9e).

\subsubsection{Strains in reinforcement}

Fig. 10 presents the values of forces in the bars of vertical reinforcement calculated based on the measurements of strains. The values for the slab P3 correspond to the load $\mathrm{Q}_{I}$. In the case of slabs $\mathrm{P} 4$ and $\mathrm{P} 6$ under the $\mathrm{Q}_{I}$ load, the values of forces in vertical reinforcement exceed the limit of proportionality between the force and strains and such a limit, for bars with the diameter of $6 \mathrm{~mm}$, was determined based on investigations as $10.05 \mathrm{kN}$. For this reason, the values of forces were determined for the slab P4 in vertical reinforcement under the load $\mathrm{Q}=25 \mathrm{kN}$ and under the load $\mathrm{Q}=35 \mathrm{kN}$ for the slab P6. In addition, linear dependencies between the strain and the force in the vertical reinforcing bars were also corresponding to such loads.

Tensile forces were generally occurring in the slab P3 in the vertical reinforcement bars (Fig. 10a). Tensile as well as compressive forces were occurring in the vertical reinforcement bars of the slab P4 and P6 (Fig. 10 b, 10 c). The bars of this reinforcement plasticised in the slab P4 under the load Q of approx. $25 \mathrm{kN}$ and in the slab P6 under the load of approx. $35 \mathrm{kN}$. Plasticisation occurred when the displacement of the top layer in relation to the bottom layer was approx. $0.1 \mathrm{~mm}$.

\subsubsection{Vertical displacements in the point}

The chart shown in Fig. 11a presents slab deflections in the point of application of the load (y) according to the loading force $(\mathrm{Q})$ in the 5th phase of loading (the loading force increases from 0 to $\mathrm{Q}_{I}$ and unloading to 0 ). The curves reveal that internal non-conservative forces are performing work for displacements, as signified by the remaining permanent deflection. In addition, the inclination of the line $y-Q$ is different for individual elements which is related to the varied stiffness of such slabs. The stiffness of the slabs, as it is proved below, depends on the type of the joint surface.

Fig. 11b shows the following relationship: the values of the force in the bar of span reinforcement $\left(\mathrm{N}_{s}\right)$ according to the loading force $(\mathrm{Q})$ in the 5 th phase of loading. The chart reveals that the limit of proportionality of strains to force was not exceeded in the bar of the main reinforcement for neither element and the limit for bars with the diameter of $20 \mathrm{~mm}$ is $147.77 \mathrm{kN}$ (see the results of supplementary investigations). 


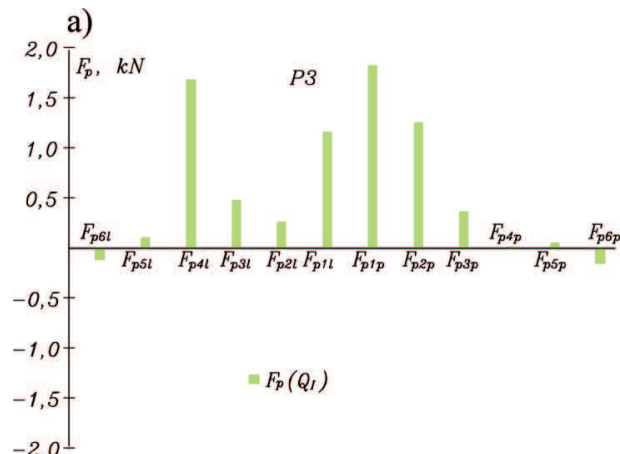

c)

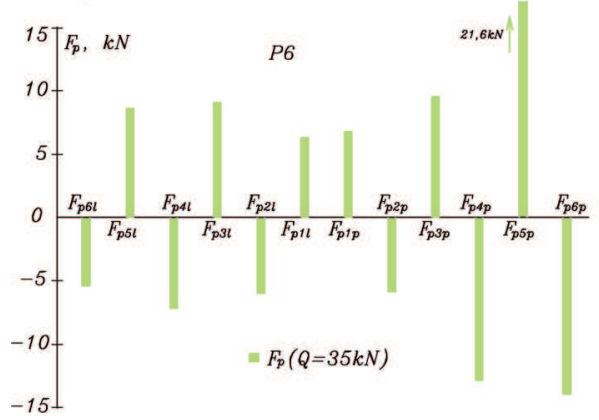

b)

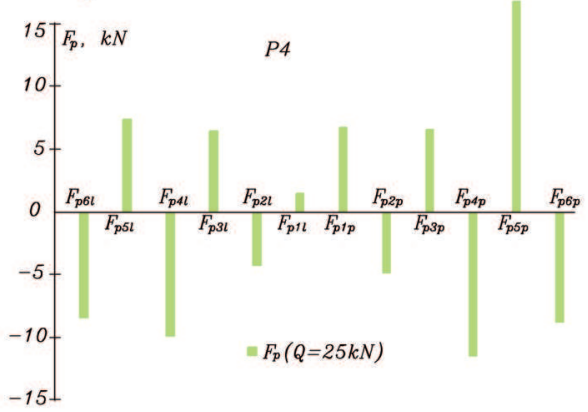

d)

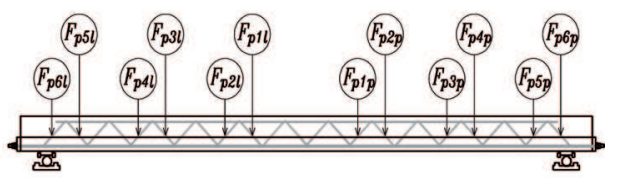

Fig. 10. The values of forces in the vertical reinforcement bars recorded under the load $\mathrm{Q}_{I}$ a) slab $\mathrm{P} 3$ b) slab P4, c) slab P6, d) measurement diagram.

a)

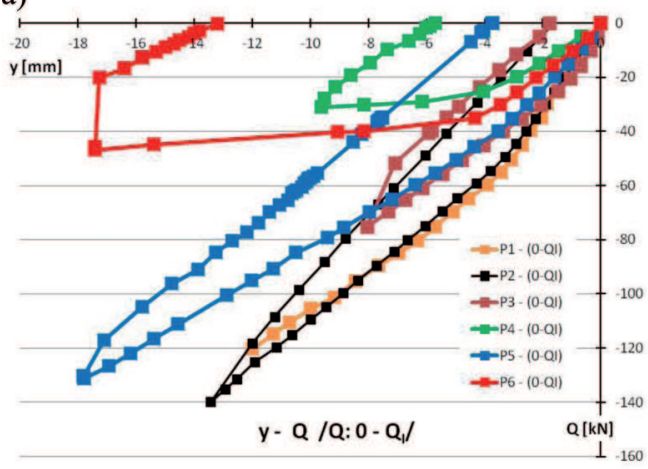

b)

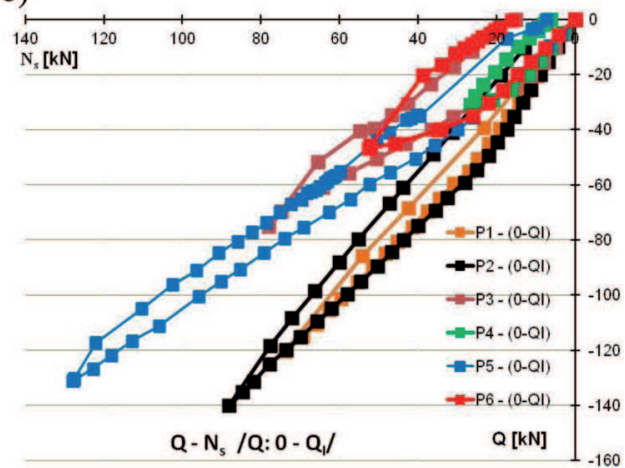

Fig. 11. The tests results of the 5th phase of loading a) slab displacement (y) in the point of application of the load $(\mathrm{Q}), \mathrm{b}$ ) force $\mathrm{N}_{s}$ in the bar of span reinforcement. 


\subsection{SLabs SUbJected to CYClic LOAdS}

Cyclic loads were performed for slabs in the "0" condition and "II" condition. The loads were performed by forcing several times the displacements of slabs (y) in the point of application of the force $\mathrm{Q}$ over the range of $-\mathrm{A}$ to $\mathrm{A}$. It was noted for all the slabs that the values measured were stabilising over the subsequent cycles, hence forming hysteresis loops. Fig. 12a illustrates an example of how a stabilised hysteresis loop is being formed by the sensor $\mathrm{w}_{5 p}$ in the slab $\mathrm{P} 4$ with the exciting force changing by the value $\Delta \mathrm{Q}$ and with the corresponding change of displacement of the bottom layer in relation to the top layer by the value $\Delta \mathrm{w}$. Fig. 12b shows how a corresponding stabilised hysteresis loop is being formed for the value $y$ when the exciting force changes by the value $\Delta \mathrm{Q}$ and with the corresponding change of displacement by the value $\Delta \mathrm{y}$. A field of the stabilised hysteresis loop in the system of coordinates (y, Q) for a dual-layer slab is designated by $\psi_{Q, w, m}$ (Fig. 12b). The corresponding field for a monolithic slab is designated by $\psi_{Q, m}$. Stabilised hysteresis loops are considered further in the article only.

a)

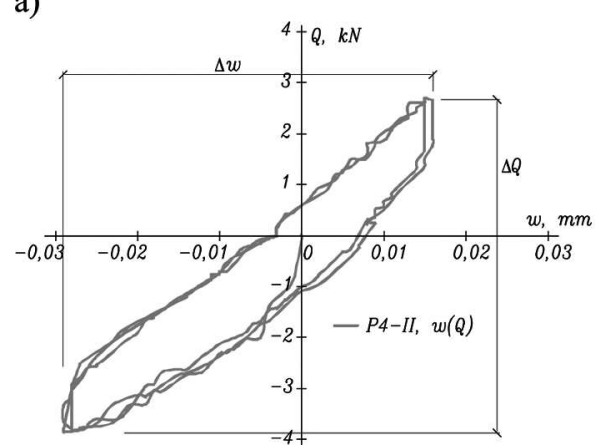

b)

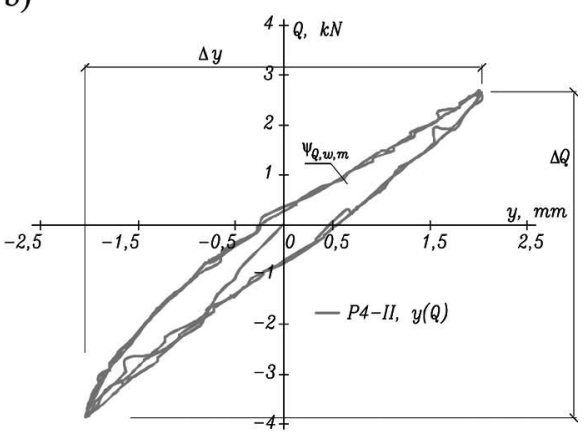

Fig. 12. The examples of tests results for the slab P4 loaded cyclically in the 10th phase of loading a) the displacement of the bottom layer in relation to the top layer recorded by the sensor $\mathrm{w}_{5 p}$, b) the vertical displacement of the slab (y) in the point of application of force $\mathrm{Q}$.

Displacements in the joint of the slabs subjected to cyclic loads were measured in all the tested elements, however, the displacements of the bottom layer in relation to the top layer in the slab P1 in the " 0 " condition at the amplitudes A of $0.1 \mathrm{~mm}$, $0.5 \mathrm{~mm}$ and $1 \mathrm{~mm}$ and in the slabs P3 and P5 for all the cycles, were lower than the measuring resolution of the apparatuses of $0.001 \mathrm{~mm}$. Hence, Fig. 13 illustrates only displacements in the joint for the slabs P4 and P6 and displacements of the slab P1 for the chosen cycles. A hysteresis loop for a given condition of the slab for various amplitudes is provided on each of the charts. The loops presented refer to the sensors showing the highest displacements for a given slab and these are the following for the individual slabs (ct. Fig. 8b): $\mathrm{P} 1-\mathrm{w}_{4 p}, \mathrm{P} 4-\mathrm{w}_{5 p}, \mathrm{P} 6-\mathrm{w}_{4 p}$. A variation of the 
exciting force $\Delta \mathrm{Q}$ and the corresponding variation of bottom layer displacement in relation to the top layer $\Delta \mathrm{w}$ was determined for each of the hysteresis loops. Likewise, the hysteresis loop charts for all the slabs were made for vertical displacement in the point and were shown in Fig. 14. The difference of vertical displacements $\Delta y$ and an area of the stabilised hysteresis loop $\psi_{Q, w, m}$ (ct. Fig. 12b) were determined for such loops. The values $\Delta \mathrm{Q}, \Delta \mathrm{w}, \Delta \mathrm{y}$ and $\psi_{Q, w, m}$ for dual-layer slabs and the value $\psi_{Q, m}$ for a monolithic slab for the slab condition "I" were collated in Table 3. The corresponding values for the "II" slab condition are listed in Table 4.

Table 3

"I" slab condition. Results of the slabs tests phases under cyclic load.

\begin{tabular}{|c|c|c|c|c|c|c|c|}
\hline $\begin{array}{l}\text { Loading } \\
\text { phase }\end{array}$ & range & $\mathrm{P} 1$ & $\mathrm{P} 2$ & $\mathrm{P} 3$ & P4 & P5 & P6 \\
\hline \multirow{4}{*}{$\begin{array}{l}1 \\
(\mathrm{~A}=0.1 \mathrm{~mm})\end{array}$} & $\Delta \mathrm{Q}$ & 12.194 & 6.858 & 8.625 & 5.568 & 5.248 & 4.298 \\
\hline & $\Delta \mathrm{w}$ & - & & - & 0.012 & - & 0.009 \\
\hline & $\Delta \mathrm{y}$ & 0.391 & 0.218 & 0.217 & 0.230 & 0.229 & 0.227 \\
\hline & $\psi_{Q, w, m}\left(\psi_{Q, m}\right)$ & 3.246 & 0.3 .3 & 1.177 & 0.982 & 0.439 & 0.227 \\
\hline \multirow{4}{*}{$\begin{array}{l}2 \\
(\mathrm{~A}=0.5 \mathrm{~mm})\end{array}$} & $\Delta \mathrm{Q}$ & 12.194 & 23.978 & 18.980 & 15.115 & 18.980 & 13.992 \\
\hline & $\Delta \mathrm{w}$ & - & & - & 0.054 & - & 0.049 \\
\hline & $\Delta y$ & 0.765 & 1.055 & 1.094 & 1.059 & 1.055 & 1.074 \\
\hline & $\psi_{Q, w, m}\left(\psi_{Q, m}\right)$ & 4.248 & 3.731 & 8.605 & 7.486 & 4.870 & 4.478 \\
\hline \multirow{4}{*}{$\begin{array}{l}3 \\
(\mathrm{~A}=1 \mathrm{~mm})\end{array}$} & $\Delta \mathrm{Q}$ & 16.896 & 36.535 & 32.359 & 24.520 & 31.655 & 21.816 \\
\hline & $\Delta \mathrm{w}$ & - & & - & 0.096 & - & 0.086 \\
\hline & $\Delta \mathrm{y}$ & 1.180 & 1.957 & 1.095 & 2.058 & 2.095 & 2.100 \\
\hline & $\psi_{Q, w, m}\left(\psi_{Q, m}\right)$ & 7.552 & 8.623 & 23.247 & 18.727 & 18.157 & 15.614 \\
\hline \multirow{4}{*}{$\begin{array}{l}4 \\
(\mathrm{~A}=2 \mathrm{~mm})\end{array}$} & $\Delta \mathrm{Q}$ & 44.837 & 39.756 & 63.914 & 33.736 & 59.208 & 37.036 \\
\hline & $\Delta \mathrm{w}$ & 0.002 & & 一 & 0.151 & - & 0.150 \\
\hline & $\Delta \mathrm{y}$ & 3.539 & 2.946 & 2.412 & 4.120 & 4.190 & 4.131 \\
\hline & $\psi_{Q, w, m}\left(\psi_{Q, m}\right)$ & 41.630 & 12.276 & 87.889 & 56.817 & 68.661 & 49.610 \\
\hline
\end{tabular}

The shape of the hysteresis loop Q(y) obtained in the plate P2 is similar to the shape of the hysteresis loop moment - curvature of $\mathrm{M}(\kappa)$ in studies of monolithic reinforced concrete beams [6].

\subsection{Results OF SUPPLEMENTARY INVESTIGATIONS}

The results of supplementary investigations of concrete are provided in Table 5, where $\mathrm{f}_{c, c u b e, s r}$ is the average compressive strength of concrete determined by investigating three cubical elements with the side of $150 \mathrm{~mm}, \mathrm{f}_{c, c y l, s r}$ stands for the average com- 
a)

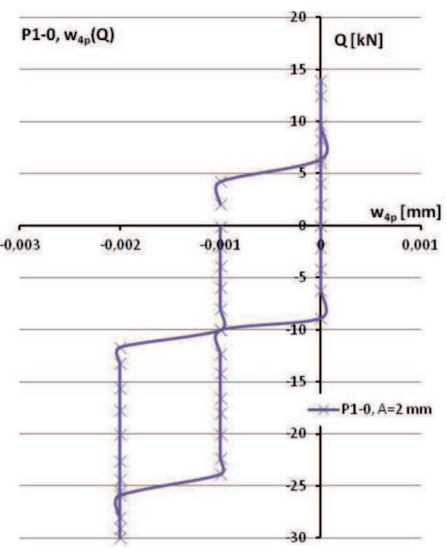

c)

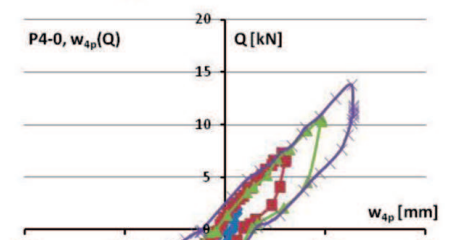

e)
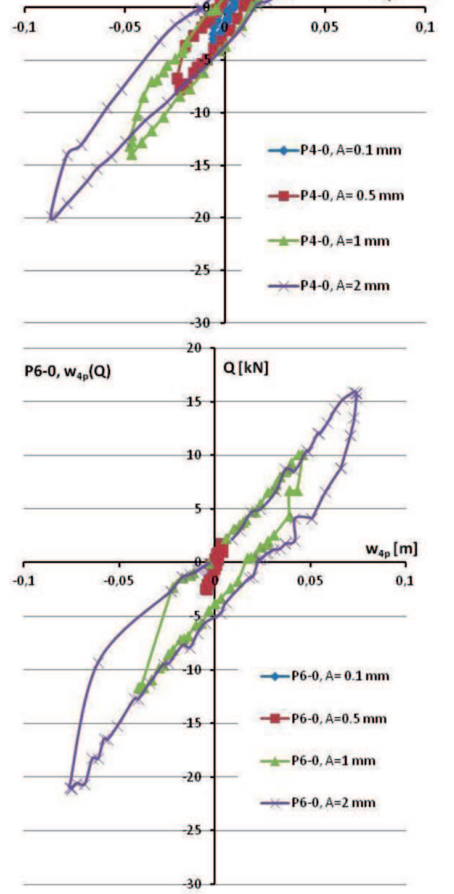

b)

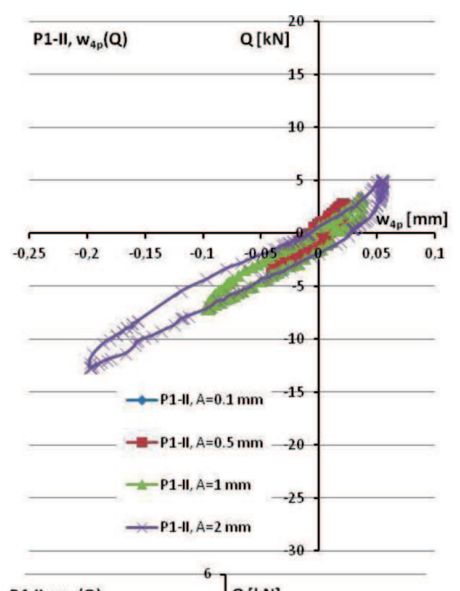

d)

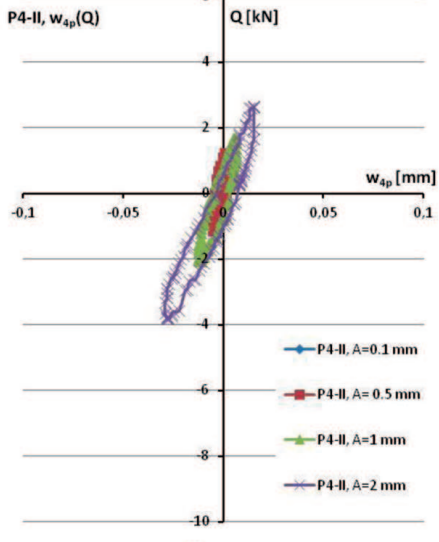

f)

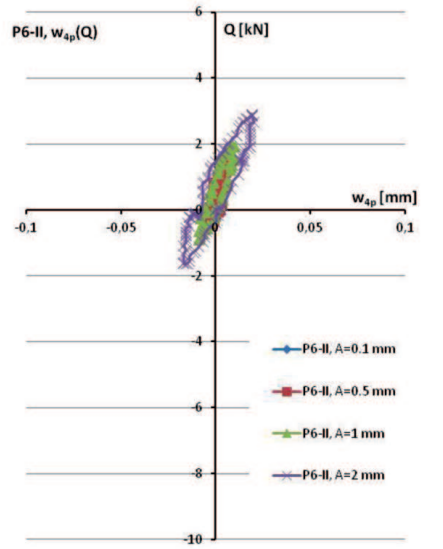

Fig. 13. Hysteresis loops of the displacement of the bottom layer in relation to the top layer for the sensors distinguished in Fig. 8b in the 1st, 2nd, 3rd and 4th phase of loading ("0" slab condition) and in the 7th, 8th, 9th and 10th phase of loading ("II" slab condition) a), b) the "0" condition of the slab P1

(P1-0) and "II" condition (P1-II), c), d) the "0" condition of the slab P4 (P4-0) and "II" condition (P4-II), e), f) the "O" condition of the slab P6 (P6-0) and "II" condition (P6-II). 
a)

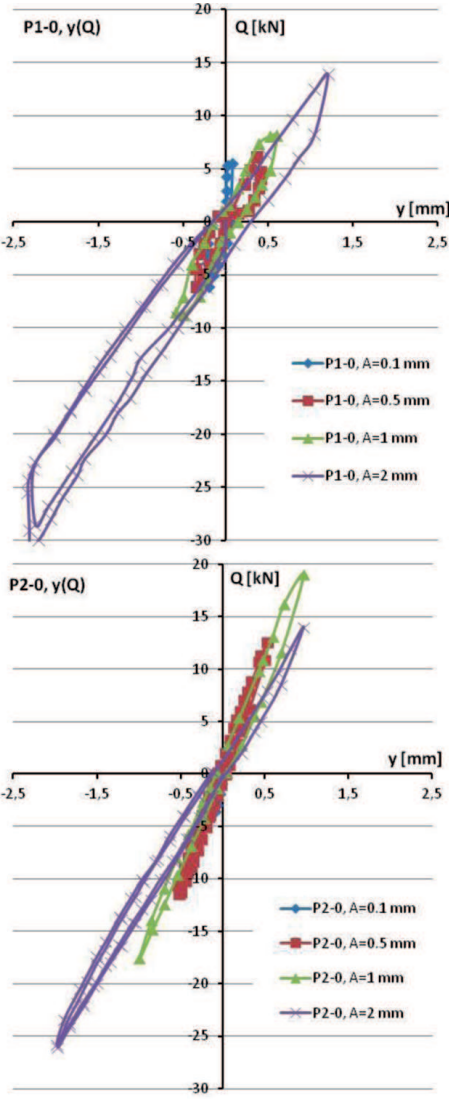

e)

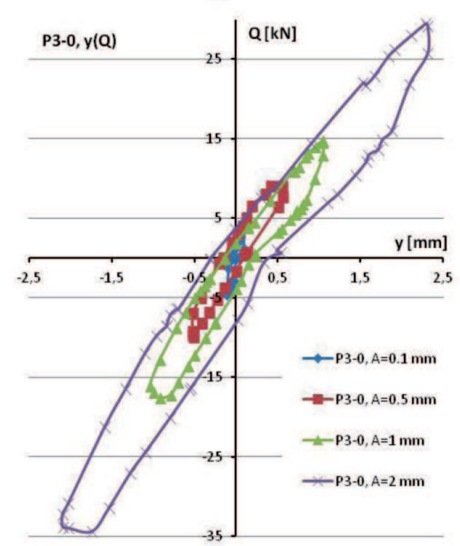

b)

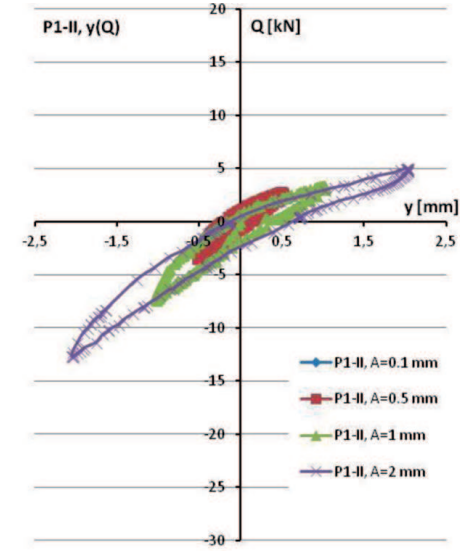

d)

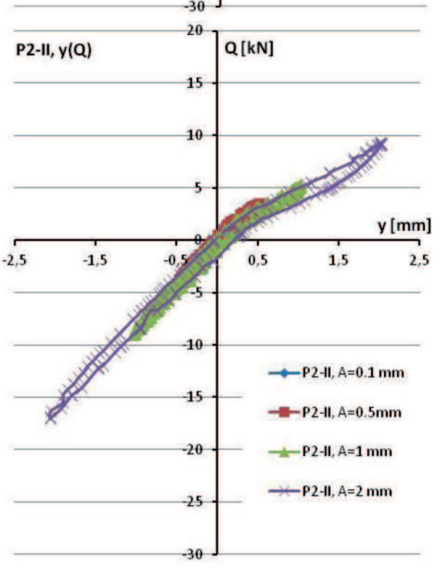

f)

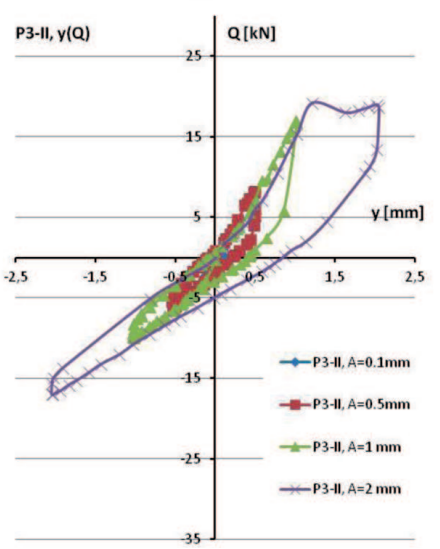


g)

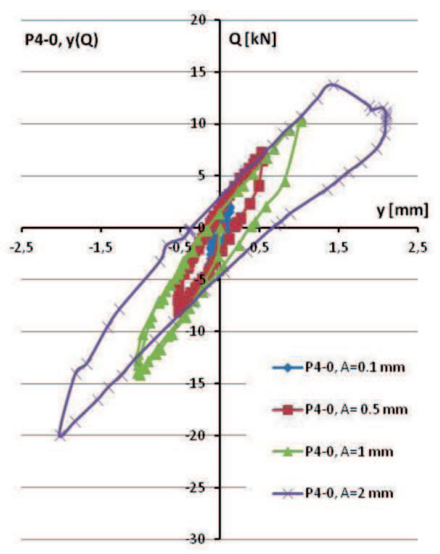

i)

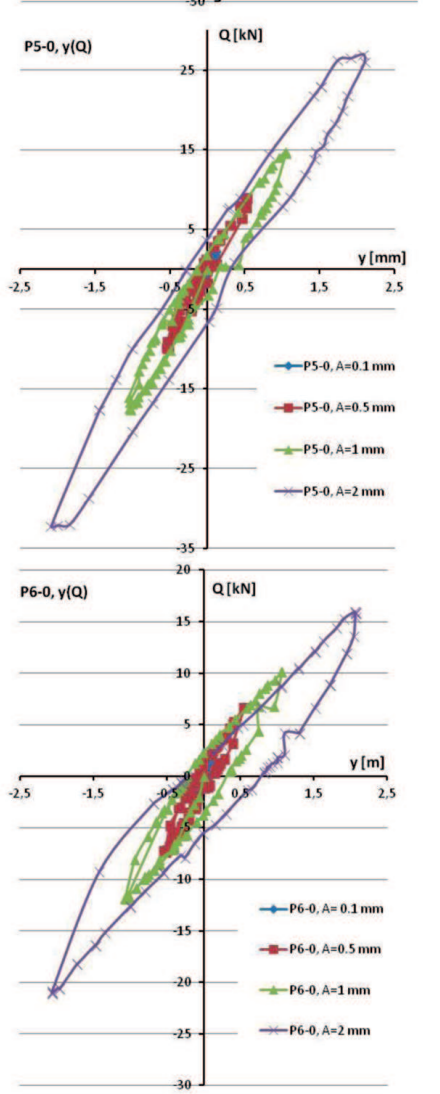

h)

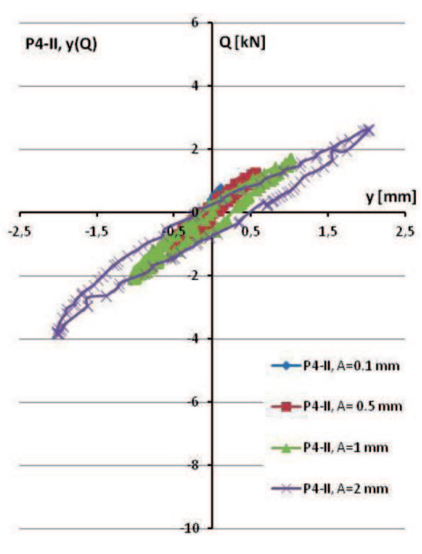

j)

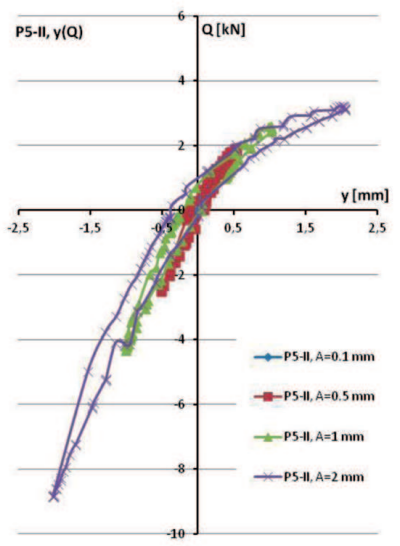

1)

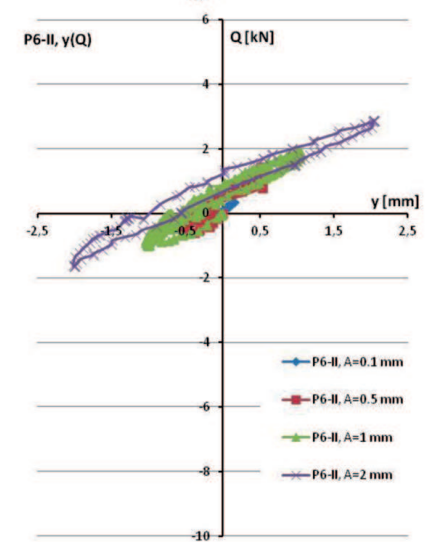

Fig. 14. Hysteresis loops of slab displacement in the point (y) caused by the load (Q) in the 1st. 2nd. 3rd and 4th phase of loading ("O" condition) and in the 7th, 8th, 9th and 10th phase of loading ("II" condition) a), b) slab P1 - "0" condition and "II" condition, c), d) slab P2 - "0" condition and "II" condition, e), f) slab P3 - "0" condition and "II" condition, g), h) slab P4 - "0" condition and "II" condition, i), j) slab P5 - "0" condition and "II" condition, k), 1) slab P6 - "0" condition and "II" condition. 
"II" slab condition. Results of the slabs tests phases under cyclic load.

\begin{tabular}{|c|c|c|c|c|c|c|c|}
\hline Loading phase & range & $\mathrm{P} 1$ & $\mathrm{P} 2$ & P3 & $\mathrm{P} 4$ & P5 & P6 \\
\hline \multirow{4}{*}{$\begin{array}{l}7 \\
(\mathrm{~A}=0.1 \mathrm{~mm})\end{array}$} & $\Delta \mathrm{Q}$ & 2.398 & 2.218 & 4.113 & 0.767 & 1.378 & 0.585 \\
\hline & $\Delta \mathrm{w}$ & 0.014 & & - & 0.002 & - & 0.002 \\
\hline & $\Delta \mathrm{y}$ & 0.217 & 0.207 & 0.217 & 0.242 & 0.226 & 0.280 \\
\hline & $\psi_{Q, w, m}\left(\psi_{Q, m}\right)$ & 0.187 & 0.096 & 0.499 & 0.017 & 0.033 & 0.021 \\
\hline \multirow{4}{*}{$\begin{array}{l}8 \\
(\mathrm{~A}=0.5 \mathrm{~mm})\end{array}$} & $\Delta \mathrm{Q}$ & 6.220 & 8.181 & 14.243 & 2.328 & 4.418 & 1.867 \\
\hline & $\Delta \mathrm{w}$ & 0.063 & & - & 0.007 & 一 & 0.009 \\
\hline & $\Delta \mathrm{y}$ & 1.032 & 1.043 & 1.041 & 1.044 & 1.045 & 1.060 \\
\hline & $\psi_{Q, w, m}\left(\psi_{Q, m}\right)$ & 2.765 & 1.362 & 6.431 & 0.400 & 0.958 & 0.457 \\
\hline \multirow{4}{*}{$\begin{array}{l}9 \\
(\mathrm{~A}=1 \mathrm{~mm})\end{array}$} & $\Delta \mathrm{Q}$ & 10.529 & 14.128 & 26.964 & 3.759 & 6.936 & 2.883 \\
\hline & $\Delta \mathrm{w}$ & 0.134 & & - & 0.018 & - & 0.019 \\
\hline & $\Delta \mathrm{y}$ & 2.043 & 2.043 & 2.059 & 2.026 & 2.038 & 2.084 \\
\hline & $\psi_{Q, w, m}\left(\psi_{Q, m}\right)$ & 7.672 & 4.078 & 16.883 & 1.764 & 2.455 & 1.585 \\
\hline \multirow{4}{*}{$\begin{array}{l}10 \\
(\mathrm{~A}=2 \mathrm{~mm})\end{array}$} & $\Delta \mathrm{Q}$ & 17.741 & 26.288 & 36.217 & 6.479 & 12.076 & 4.545 \\
\hline & $\Delta \mathrm{w}$ & 0.254 & & - & 0.044 & - & 0.037 \\
\hline & $\Delta \mathrm{y}$ & 4.086 & 4.091 & 4.101 & 4.052 & 4.065 & 4.060 \\
\hline & $\psi_{Q, w, m}\left(\psi_{Q, m}\right)$ & 17.894 & 10.962 & 57.474 & 5.518 & 6.868 & 3.736 \\
\hline
\end{tabular}

pressive strength determined with three $\phi 150 / 300 \mathrm{~mm}$ cylinders, and $\mathrm{f}_{c t, \phi, s r}$ means the average tensile strength determined in a crack test of three $\phi 160 / 150 \mathrm{~mm}$ cylinders. The secants modulus of the elasticity $\mathrm{E}_{c m}$ for the concrete of each layer were determined using one cylindrical $\phi 160 / 150 \mathrm{~mm}$ specimen within the limits of $0 \div 0.4 \cdot \mathrm{f}_{c, c y l}$. The limit of proportionality of force to the strains of bars with the diameter of $20 \mathrm{~mm}$ was $147.77 \mathrm{kN}$, and of bars with the diameter of $6 \mathrm{~mm}-10.05 \mathrm{kN}$. The values of tensile forces for bars were, respectively, $199.24 \mathrm{kN}$ and $12.72 \mathrm{kN}$.

\section{ANALYsis of TESTS RESUlts}

The purpose of the tests results' interpretation given below is to determine the parameters of the models described in Chapter 2. The following will be estimated for the individual slabs:

- the contact layer stiffness $\left(\mathrm{k}_{q, w}\right)$ estimating the substitute stiffness $\mathrm{k}_{q, w, z}$ in slabs loaded monotonically and the resultant stiffness $\mathrm{k}_{q, w, x}$ in slabs loaded cyclically,

- monolithic slab stiffness in the point of application of force $\left(\mathrm{k}_{Q, m}\right)$ estimating the resultant stiffness of a model of a monolithic slab with a single degree of freedom $\left(\mathrm{k}_{Q, m, x}\right)$, 
Results of supplementary tests for concrete.

\begin{tabular}{|c|c|c|c|c|c|}
\hline & & $\mathrm{f}_{c, c u b e, s r}[\mathrm{MPa}], \mathrm{s}_{r}$ & $\mathrm{f}_{c, c y l, s r}[\mathrm{MPa}], \mathrm{s}_{r}$ & $\mathrm{f}_{c t, \phi, s r}[\mathrm{MPa}], \mathrm{s}_{r}$ & $\mathrm{E}_{c m}[\mathrm{GPa}]$ \\
\hline \multirow{2}{*}{ P1 } & Top layer & $60.28 ; 7.55$ & $50.02 ; 7.47$ & $3.71 ; 0.49$ & 42.23 \\
\cline { 2 - 6 } & Bottom layer & $49.10 ; 9.88$ & $38.77 ; 7.16$ & $3.12 ; 0.21$ & 33.83 \\
\hline \multirow{2}{*}{ P2 } & Monol. slab & $51.76 ; 9.72$ & $43.78 ; 10.17$ & $3.13 ; 0.18$ & 37.93 \\
\hline \multirow{2}{*}{ P3 } & Top layer & $50.59 ; 1.51$ & $41.07 ; 1.46$ & $2.45 ; 0.21$ & 35.22 \\
\cline { 2 - 6 } & Bottom layer & $58.37 ; 3.06$ & $45.48 ; 3.88$ & $2.62 ; 0.34$ & 37.79 \\
\hline \multirow{2}{*}{ P4 } & Top layer & $48.74 ; 3.30$ & $39.65 ; 4.68$ & $2.31 ; 0.10$ & 37.89 \\
\cline { 2 - 6 } & Bottom layer & $50.39 ; 2.45$ & $41.20 ; 1.08$ & $2.99 ; 0.20$ & 37.44 \\
\hline \multirow{2}{*}{ P5 } & Top layer & $51.37 ; 1.43$ & $39.59 ; 0.33$ & $2.10 ; 0.41$ & 36.63 \\
\cline { 2 - 6 } & Bottom layer & $52.34 ; 1.87$ & $38.33 ; 1.79$ & $2.63 ; 0.29$ & 33.02 \\
\hline \multirow{2}{*}{ P6 } & Top layer & $44.04 ; 2.81$ & $46.90 ; 2.03$ & $2.72 ; 0.34$ & 32.64 \\
\cline { 2 - 6 } & Bottom layer & $46.72 ; 1.21$ & $40.73 ; 3.08$ & $1.98 ; 0.25$ & 31.08 \\
\hline
\end{tabular}

- component stiffness of the composite slab in the point of application of force $\left(\mathrm{k}_{Q, w}\right)$ estimating the resultant of the stiffness component of the composite slab model with a single degree of freedom $\mathrm{k}_{Q, w, x}$,

- the energy dissipation coefficients $\chi_{Q, m}$ and $\chi_{Q, w, m}$.

\subsection{ESTIMATION OF STIFFNESS OFCONTACT LAYER}

The distribution of horizontal displacements of the bottom layer in relation to the top layer determined according to a contact layer model is a periodic function (2.2). The amplitude of this function will set a basis for contact layer stiffness estimation.

Under the monotonically growing load, stiffness of contact layer in the continuous contact layer model is represented by the substitute stiffness $\mathrm{k}_{q, w, z}$. Stiffness estimation will be done for stiffness of the contact layer determined according to the following relationship:

$$
k_{q, w}=\frac{3 q}{w_{\max }}
$$

where $\mathrm{w}_{\max }$ is the highest displacement value recorded according to the contact layer length with the horizontal shearing force with the $q$ value.

Stiffness of contact layer in the model subjected to cyclic loads is represented by the resultant stiffness $\mathrm{k}_{q, w, x}$, to be estimated by stiffness of contact layer determined according to the following relationship

$$
k_{q, w}=\frac{3 \Delta q_{s j}}{\Delta w},
$$

where $\Delta \mathrm{q}$ is a variation of horizontal shearing force and $\Delta \mathrm{w}$ is the highest variation of displacement recorded for contact layer length. 
5.1.1. Stiffness determined according to monotonic load

Fig. 15a shows the contact layer stiffness $\mathrm{k}_{q, w}$ determined according to (5.1), under the growing load in the 5 th phase of loading for the investigated composite slabs.

a)

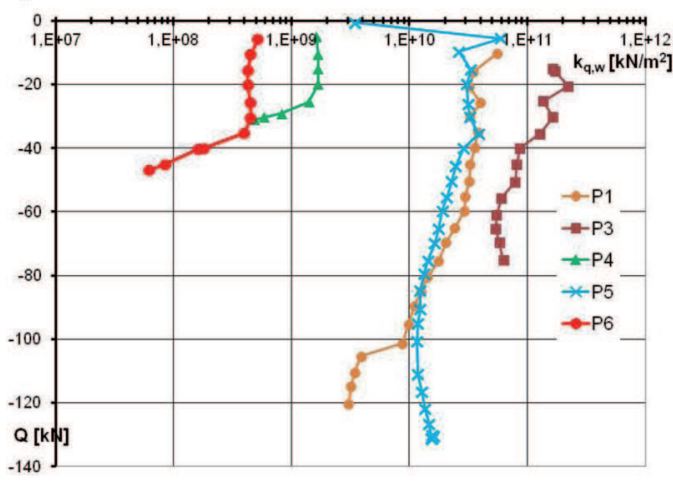

d)

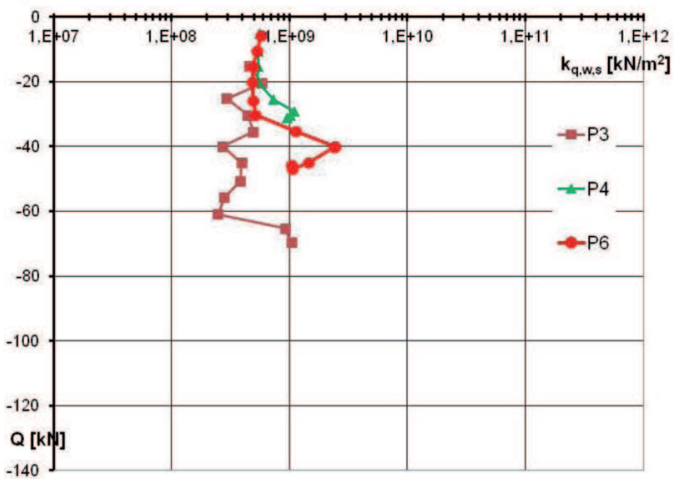

b)
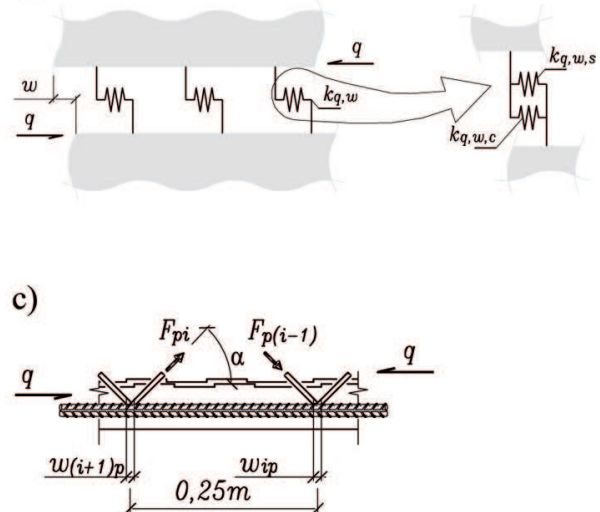

Fig. 15. Contact layer stiffness determined for the 5th phase of loading a) stiffness $\mathrm{k}_{q, w}$ approximating stiffness $\mathrm{k}_{q, w, z}, \mathrm{~b}$ ) stiffness $\mathrm{k}_{q, w, s}$ of contact layer for which reinforcement is responsible.

It was assumed that contact layer stiffness $\left(\mathrm{k}_{q, w}\right)$ consists of the concrete stiffness of the contact layer designated as $\mathrm{k}_{q, w, c}$ and the stiffness of vertical reinforcement in the joint designated as $\mathrm{k}_{q, w, s}$ (Fig. 15b) working in the parallel system

$$
k_{q, w}=k_{q, w, s}+k_{q, w, c} .
$$

The stiffness of vertical reinforcement in the joint $\mathrm{k}_{q, w, s}$, the same as for (5.1), was calculated as $1 / 3$ of the quotient of force projection in vertical reinforcement to hori- 
zontal direction referred to the length of the composite where the force exists $(0.25 \mathrm{~m}$ - Fig. 15c) through the appropriate displacements (Fig. 15c)

$$
k_{q, w, s}=\frac{\left(F_{p i}+F_{p(i-1)}\right) \cos \alpha}{3 \cdot 0.25\left(w_{(i+1) p}+w_{i p}\right)} .
$$

The "i" index equal to 5.4 or 2 was adopted in such a way that the denominator value corresponds to the maximum value of displacement, the same as for the relationship (5.1). Fig. 15d shows the stiffness of vertical reinforcement achieved in the joint under the growing load in the 5th phase of loading.

Table 6 lists the stiffnesses determined according to (5.1), (5.3) and (5.4) i.e. $\mathrm{k}_{q, w}$ and $\mathrm{k}_{q, w, s}$ in the initial phase of loading where stiffness has not substantially changed and the corresponding values correspond to $\mathrm{Q}_{I}$ force.

Table 6

Estimation of contact layer stiffness in the 5th phase of loading.

\begin{tabular}{|c|c|c|c|c|c|}
\hline \multirow{2}{*}{ Element } & \multicolumn{3}{|c|}{ Stiffness for force range Q } & \multicolumn{2}{c|}{ Stiffness corresponding to force $\mathrm{Q}_{I}$} \\
\cline { 2 - 6 } & Force range Q & $\mathrm{k}_{q, w}$ & $\mathrm{k}_{q, w, s}$ & $\mathrm{Q}_{I}$ & $\mathrm{k}_{q, w}$ \\
\cline { 2 - 6 } & $\mathrm{kN}$ & $\mathrm{GPa}$ & $\mathrm{GPa}$ & $\mathrm{kN}$ & $\mathrm{GPa}$ \\
\hline $\mathrm{P} 1$ & $16 \div 60$ & 33.6 & no measurement & 120 & 3.04 \\
\hline $\mathrm{P} 3$ & $15 \div 55$ & 125 & 0.401 & 75 & 62.8 \\
\hline P4 & $5 \div 25$ & 1.62 & 0.583 & 31 & 0.584 \\
\hline P5 & $9 \div 70$ & 26.0 & - & 131 & 15.5 \\
\hline P6 & $10 \div 35$ & 0.434 & 0.609 & 47 & 0.062 \\
\hline
\end{tabular}

The list shown in Table 6 shows that the contact layer produced by joining a smooth surface obtained from shuttering (P3 slab) is characterised by the highest stiffness, and the lowest value applies to a layer produced by joining a smooth surface - levelled with a trowel (P6 slab) with cement wash released on the surface. The stiffness of the layer produced based on a smooth surface is approx. five times higher than the stiffness of the layer made by joining a surface with indentations (P5 slab). This finding is contrary to the one expected. It is the author's opinion that the explanation for this is that the $5 / 5 \mathrm{~mm}$ indentations were filled with concrete with lower stiffness or that the concrete of the top layer has not filled tightly the indentations made in the bottom layer. The chart in Fig. 15a shows that the contact layer stiffness $\mathrm{k}_{q, w}$ is not a permanent parameter and its value is decreasing along with a growing load.

Roughly, a double decrease in the value of $\mathrm{k}_{q, w}$ was observed within the investigated range of loads in the case of a layer produced by joining the following surfaces: a smooth surface produced as a mould casting - the P3 slab - (from approx. $125 \mathrm{GPa}$ to approx. $63 \mathrm{GPa}$ ) and a surface with indentations - the P5 slab - (from approx. $26 \mathrm{GPa}$ to approx. $15 \mathrm{GPa}$ ). In the case of a smooth trowelled surface on which cement wash has released about a tenfold decrease was seen from approx. $0.43 \mathrm{GPa}$ to approx. $0.06 \mathrm{GPa}$ 
in the P6 slab and from approx. $34 \mathrm{GPa}$ to approx. $3 \mathrm{GPa}$ in the P1 slab. The similar phenomenon was discussed in [7]. Another remark important from a practical point of view is the small impact of vertical reinforcement on contact layer stiffness. For example, the impact is less than $1 \%((0.401 / 125) \cdot 100 \%)$ for a smooth surface produced with a mould - the P3 slab.

\subsubsection{Stiffness determined according to the cyclic load}

The resultant stiffness of contact layer $\left(\mathrm{k}_{q, w, x}\right)$ was estimated with the contact layer stiffness $\left(\mathrm{k}_{q, w}\right)$ according to (5.2). The value $\Delta \mathrm{q}$ and the corresponding values $\Delta \mathrm{w}$ were taken from Table 3 for the "0" condition and from Table 4 for the "II" condition. The determined stiffnesses of slab $\mathrm{k}_{q, w}$ for the " 0 " condition are listed in Table 7 and in Table 8 for the "II" condition.

Table 7

" 0 " slab condition. Estimation of the resultant contact layer stiffness $\left(\mathrm{k}_{q, w, x}\right)$ with stiffness $\mathrm{k}_{q, w}[\mathrm{~N} / \mathrm{m}]$ according to (5.2).

\begin{tabular}{|c|c|c|c|c|c|c|}
\hline Loading phase (amplitude A) & $\mathrm{P} 1$ & $\mathrm{P} 2$ & $\mathrm{P} 3$ & $\mathrm{P} 4$ & P5 & P6 \\
\hline $1(\mathrm{~A}=0.1 \mathrm{~mm})$ & - & & - & $5.16 \cdot 10^{9}$ & - & $5.31 \cdot 10^{9}$ \\
\hline $2(\mathrm{~A}=0.5 \mathrm{~mm})$ & - & & - & $3.11 \cdot 10^{9}$ & - & $3.17 \cdot 10^{9}$ \\
\hline $3(\mathrm{~A}=1 \mathrm{~mm})$ & - & & - & $2.84 \cdot 10^{9}$ & - & $2.82 \cdot 10^{9}$ \\
\hline $4(\mathrm{~A}=2 \mathrm{~mm})$ & $69.1 \cdot 10^{9}$ & & - & $2.48 \cdot 10^{9}$ & - & $2.74 \cdot 10^{9}$ \\
\hline
\end{tabular}

Table 8

"II" slab condition. Estimation of resultant contact layer stiffness $\left(\mathrm{k}_{q, w, x}\right)$ with stiffness $\mathrm{k}_{q, w}[\mathrm{~N} / \mathrm{m}]$ according to (5.2).

\begin{tabular}{|c|c|c|c|c|c|c|}
\hline Loading phase (amplitude A) & $\mathrm{P} 1$ & $\mathrm{P} 2$ & $\mathrm{P} 3$ & $\mathrm{P} 4$ & P5 & P6 \\
\hline $7(\mathrm{~A}=0.1 \mathrm{~mm})$ & $1.90 \cdot 10^{9}$ & & - & $4.26 \cdot 10^{9}$ & - & $3.25 \cdot 10^{9}$ \\
\hline $8(\mathrm{~A}=0.5 \mathrm{~mm})$ & $1.10 \cdot 10^{9}$ & & - & $3.70 \cdot 10^{9}$ & - & $2.30 \cdot 10^{9}$ \\
\hline $9(\mathrm{~A}=1 \mathrm{~mm})$ & $0.873 \cdot 10^{9}$ & & - & $2.32 \cdot 10^{9}$ & - & $1.69 \cdot 10^{9}$ \\
\hline $10(\mathrm{~A}=2 \mathrm{~mm})$ & $0.776 \cdot 10^{9}$ & & - & $1.64 \cdot 10^{9}$ & - & $1.36 \cdot 10^{9}$ \\
\hline
\end{tabular}

The stiffnesses $\mathrm{k}_{q, w}$ determined independently of the analysed condition of the slabs are decreasing as amplitude $\mathrm{A}$ is growing. The lowest stiffness of the contact layer was seen for the slab P1 being in the "II" condition with the amplitude of A=2 mm, when $\mathrm{k}_{q, w}$ was $0.779 \cdot 10^{9} \mathrm{~N} / \mathrm{m}^{2}$. The highest stiffness of $69.1 \cdot 10^{9} \mathrm{~N} / \mathrm{m}^{2}$ was managed to be determined for the slab P1 being in the " 0 " condition with the amplitude of A=2 mm. 
The contact layer stiffness of the slabs P3 and P5 was much higher, but, as there was no measurement of displacements smaller than $0.001 \mathrm{~mm}$, the contact layer stiffness $\left(\mathrm{k}_{q, w}\right)$ of the slabs under cyclic loading was not determined successfully. A variation of contact layer stiffness $\mathrm{k}_{q, w}$ of the slabs P1, P4 and P6 is shown in a chart in Fig. 16a.

a)

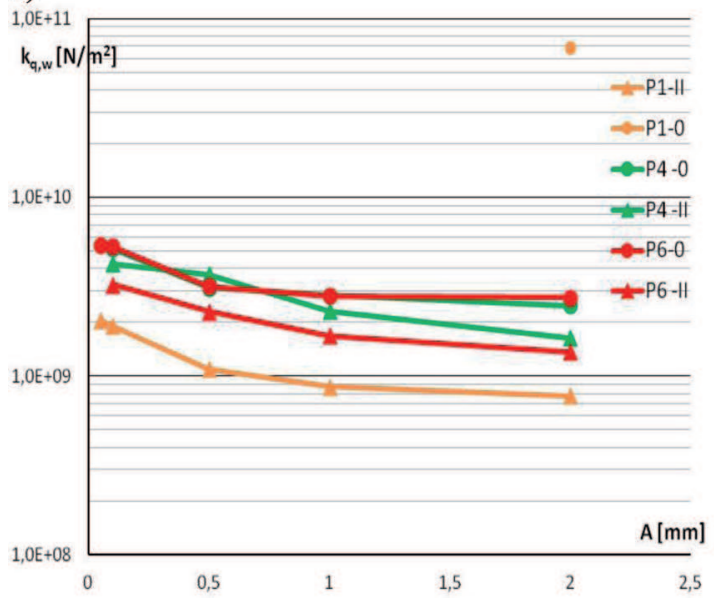

b)

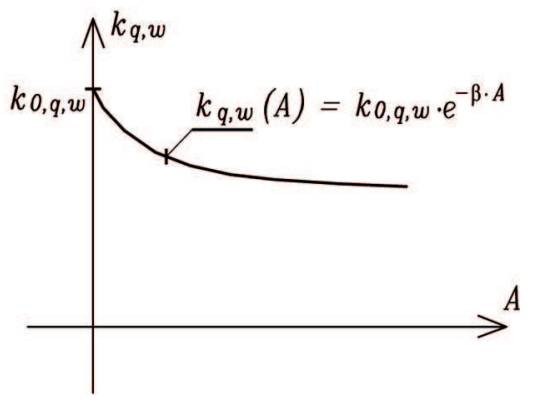

Fig. 16. Contact layer stiffness $\mathrm{k}_{q, w}$ approximating stiffness $\mathrm{k}_{q, w, x}$ as a variable dependent on the amplitude a) results of investigations, b) phenomenon overview.

It was revealed after analysing the results from Fig. 16a that contact layer stiffness $\mathrm{k}_{q, w}$ of the slabs is a function of amplitude (A) and that this relationship can be interpolated with the exponential curve (Fig. 16b)

$$
k_{q, w}(A)=k_{0, q, w} e^{-\beta A},
$$

where $\mathrm{k}_{0, q, w}$ is the initial contact layer stiffness, and the exponent $\beta$ describes the disappearance of contact layer stiffness as the amplitude $\mathrm{A}$ is growing. The $\mathrm{k}_{0, q, w}$ value in the elements P4 and P6 in the " 0 " condition and in the "II" condition was determined as constant and equal $4 \cdot 10^{9} \mathrm{~N} / \mathrm{m}^{2}$. It was not possible to determine $\mathrm{k}_{0, q, w}$ in the P1 slab in the " 0 " condition due to bottom layer displacements in relation to the top layer smaller than the apparatus' measuring resolution. Stiffness $\mathrm{k}_{0, q, w}$ of the P1 slab in the "II" condition decreased to $2 \cdot 10^{9} \mathrm{~N} / \mathrm{m}^{2}$ due to slab delamination.

\subsection{Estimation OF SLABS STIFFNESS ACCORDING TO A MODEL WITH A SINGLE DEGREE OF FREEDOM}

The resultant stiffness of a composite slab model with a single degree of freedom $\left(\mathrm{k}_{Q, w, m, x}\right)$ is estimated in the point of application of force $\left(\mathrm{k}_{Q, w, m}\right)$ with the stiffness of composite slab determined during the investigations. Similarly, the resultant stiffness of a monolithic slab with a single degree of freedom $\left(\mathrm{k}_{Q, m, x}\right)$ is estimated with the 
stiffness of a monolithic slab in point $\left(\mathrm{k}_{Q, m}\right)$ determined in the investigations. The stiffnesses are determined according to the following relationship

$$
k_{Q, w, m}=\frac{\Delta Q}{\Delta y} ; \quad k_{Q, m}=\frac{\Delta Q}{\Delta y},
$$

where $\Delta \mathrm{Q}$ is a variation of the excitation force and $\Delta \mathrm{y}$ is the corresponding variation in vertical displacement. The stiffnesses of the slabs corresponding to the " 0 " condition were determined according to the values $\Delta \mathrm{Q}$ and $\Delta \mathrm{y}$ originating from Tab. 3 with the stiffnesses given in Tab. 9. On the other hand, the stiffnesses of the slabs corresponding to the "II" condition were determined according to the values $\Delta \mathrm{Q}$ and $\Delta \mathrm{y}$ derived from Tab. 4 with the stiffnesses given in Tab. 10. In addition, a stiffness component for which the contact layer $\left(\mathrm{k}_{Q . w}\right)$ is responsible is provided in Tab. 9 and Tab. 10 determined according to the relationship (2.13).

Table 9

The calculated stiffnesses of composite slabs in the point $\left(\mathrm{k}_{Q, w, m}\right)$ and in the monolithic slab $\left(\mathrm{k}_{Q, m}\right)$ according to (5.6) expressed in GN/m in the "0" condition.

\begin{tabular}{|c|c|c|c|c|c|c|c|}
\hline $\begin{array}{c}\text { Loading phase } \\
\text { (amplitude } \mathrm{A})\end{array}$ & $\begin{array}{c}\text { Value } \\
\left(\mathrm{k}_{Q, m, x} \text { applies to } \mathrm{P} 2\right)\end{array}$ & $\mathrm{P} 1$ & $\mathrm{P} 2$ & $\mathrm{P} 3$ & $\mathrm{P} 4$ & $\mathrm{P} 5$ & $\mathrm{P} 6$ \\
\hline \multirow{2}{*}{$1(\mathrm{~A}=0.1 \mathrm{~mm})$} & $\mathrm{k}_{Q, w, m}\left(\mathrm{k}_{Q, m, x}\right)$ & 31.2 & 31.4 & 39.7 & 24.2 & 22.9 & 18.9 \\
\cline { 2 - 8 } & $\mathrm{k}_{Q, w, x}$ & 4690 & & $>1000$ & 106 & 84.9 & 47.7 \\
\hline \multirow{2}{*}{$2(\mathrm{~A}=0.5 \mathrm{~mm})$} & $\mathrm{k}_{Q, w, m}\left(\mathrm{k}_{Q, m, x}\right)$ & 15.9 & 22.8 & 17.4 & 14.3 & 18.0 & 13.0 \\
\cline { 2 - 8 } & $\mathrm{k}_{Q, w, x}$ & 53.2 & & 73.2 & 38.3 & 85.9 & 30.5 \\
\hline \multirow{2}{*}{$3(\mathrm{~A}=1 \mathrm{~mm})$} & $\mathrm{k}_{Q, w, m}\left(\mathrm{k}_{Q, m, x}\right)$ & 14.3 & 18.7 & 15.4 & 11.9 & 15.1 & 10.4 \\
\cline { 2 - 8 } & $\mathrm{k}_{Q, w, x}$ & 60.8 & & 89.4 & 32.9 & 79.2 & 23.4 \\
\hline \multirow{2}{*}{$4(\mathrm{~A}=2 \mathrm{~mm})$} & $\mathrm{k}_{Q, w, m}\left(\mathrm{k}_{Q, m, x}\right)$ & 12.7 & 13.5 & 14.5 & 8.19 & 14.1 & 8.97 \\
\cline { 2 - 8 } & $\mathrm{k}_{Q, w, x}$ & 208 & & $>1000$ & 20.8 & $>1000$ & 26.7 \\
\hline
\end{tabular}

The determined stiffnesses of the composite slabs $\mathrm{k}_{Q, w, m}$ and of the monolithic slab $\mathrm{k}_{Q, m}$ decrease according to the amplitude as shown in Fig. 17a. The calculated component stiffnesses of the composite slabs $\mathrm{k}_{Q, w}$ accompanied by delamination when reaching the force $\mathrm{Q}_{I I}$, i.e. the slabs $\mathrm{P} 1, \mathrm{P} 4$ and $\mathrm{P} 5$, also decrease as the amplitude is growing. On the other hand, in the case of the composite slabs P3 and P5 that were not accompanied by delamination after reaching the force $\mathrm{Q}_{I I}$, a variation in the stiffness $\mathrm{k}_{Q, w}$ according to the changing amplitude is not certain. The stiffness $\mathrm{k}_{Q, w}$ determined in such slabs, with the amplitude changing from $0.1 \mathrm{~mm}$ to $0.5 \mathrm{~mm}$, decreased and with the amplitude changing from $1 \mathrm{~mm}$ to $2 \mathrm{~mm}$, the determined stiffness $\mathrm{k}_{Q . w}$ was approximately constant. In any case, the impact of the stiffness $\mathrm{k}_{Q, w}$ on the stiffness $\mathrm{k}_{Q, w, m}$ for such slabs is not significant. The stiffnesses $\mathrm{k}_{Q, w}$, determined according to the amplitude (A) are shown in Fig. 17b. 
ESTIMATION OF STIFFNESS AND ENERGY DISSIPATION FOR THE MODELS OF REINFORCED-CONCRETE...

Table 10

The calculated stiffnesses of composite slabs in the point $\left(\mathrm{k}_{Q, w, m}\right)$ and in the monolithic slab $\left(\mathrm{k}_{Q, m}\right)$ according to (5.6) expressed in $\mathrm{GN} / \mathrm{m}$ in the "II" condition.

\begin{tabular}{|c|c|c|c|c|c|c|c|}
\hline $\begin{array}{c}\text { Loading phase } \\
\text { (amplitude A) }\end{array}$ & $\begin{array}{c}\text { Value } \\
\left(\mathrm{k}_{Q, m, x} \text { applies to } \mathrm{P} 2\right)\end{array}$ & $\mathrm{P} 1$ & $\mathrm{P} 2$ & $\mathrm{P} 3$ & $\mathrm{P} 4$ & $\mathrm{P} 5$ & $\mathrm{P} 6$ \\
\hline \multirow{2}{*}{$7(\mathrm{~A}=0.1 \mathrm{~mm})$} & $\mathrm{k}_{Q, w, m}\left(\mathrm{k}_{Q, m, x}\right)$ & 11.1 & 10.7 & 19.0 & 3.17 & 6.10 & 2.09 \\
\cline { 2 - 8 } & $\mathrm{k}_{Q, w, x}$ & $>1000$ & & $>1000$ & 4.5 & 14.2 & 2.60 \\
\hline \multirow{2}{*}{$8(\mathrm{~A}=0.5 \mathrm{~mm})$} & $\mathrm{k}_{Q, w, m}\left(\mathrm{k}_{Q, m, x}\right)$ & 6.03 & 7.84 & 13.7 & 2.23 & 4.23 & 1.76 \\
\cline { 2 - 8 } & $\mathrm{k}_{Q, w, x}$ & 26 & & $>1000$ & 3.12 & 9.17 & 2.27 \\
\hline \multirow{2}{*}{$9(\mathrm{~A}=1 \mathrm{~mm})$} & $\mathrm{k}_{Q, w, m}\left(\mathrm{k}_{Q, m, x}\right)$ & 5.15 & 6.92 & 13.1 & 1.86 & 3.40 & 1.38 \\
\cline { 2 - 8 } & $\mathrm{k}_{Q, w, x}$ & 20.2 & & $>1000$ & 2.54 & 6.70 & 1.73 \\
\hline \multirow{2}{*}{$10(\mathrm{~A}=2 \mathrm{~mm})$} & $\mathrm{k}_{Q, w, m}\left(\mathrm{k}_{Q, m, x}\right)$ & 4.34 & 6.43 & 8.83 & 1.60 & 2.97 & 1.12 \\
\cline { 2 - 8 } & $\mathrm{k}_{Q, w, x}$ & 13.4 & & $>1000$ & 2.13 & 5.52 & 1.36 \\
\hline
\end{tabular}

a)

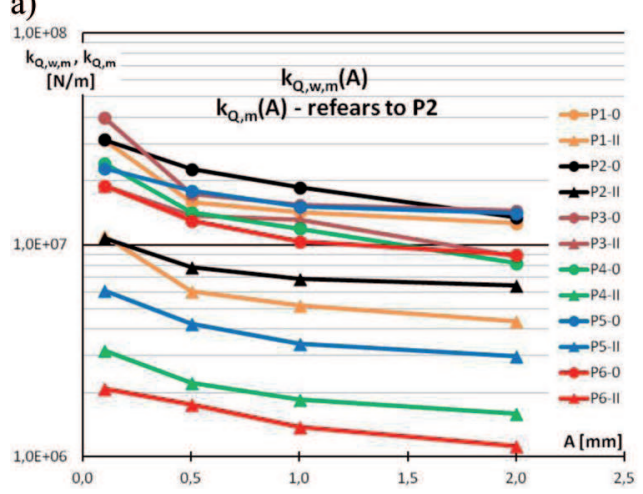

b)

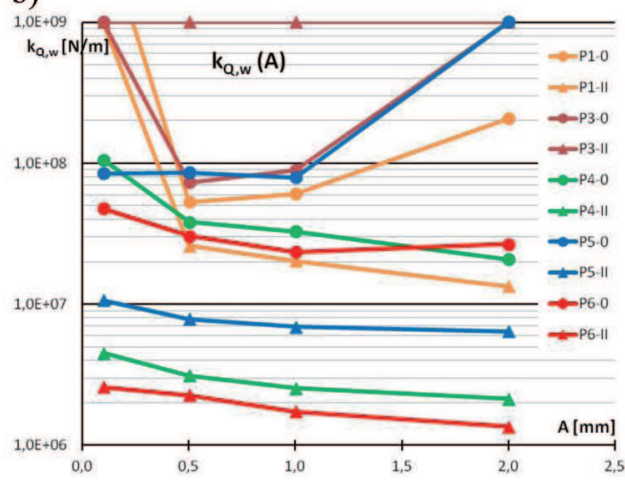

Fig. 17. The stiffnesses of slabs in the "0" condition and "II" condition as the variables dependent on the amplitude (A) a) stiffness of composite slabs in the point $\left(\mathrm{k}_{Q, w, m}\right.$ applies to the slabs P1, P3, P4, P5, P6) and stiffness of a monolithic slab in the point $\left(\mathrm{k}_{Q, m}\right.$ applies to the slab P2) estimating the stiffnesses $\mathrm{k}_{Q, w, m, x}$ and $\left.\mathrm{k}_{Q, m, x} \mathrm{~b}\right)$ the component stiffness of the slabs for which the contact layer is responsible $\left(\mathrm{k}_{Q, w}\right)$.

\subsection{STIFfNESS OF CONTACT LAYER AND A COMPONENT OF STIFFNESS OF COMPOSITE SLAB}

The analyses performed to date show that the component stiffnesses of a composite slab in the point $\mathrm{k}_{Q, w}$ depends on two parameters. The first one is contact layer stiffness $\left(\mathrm{k}_{q, w}\right)$ and the other amplitude $(\mathrm{A})$.

The impact of stiffness $\mathrm{k}_{q, w}$ on stiffness $\mathrm{k}_{Q, w}$ was analysed on a chart made in the coordinates $\mathrm{k}_{q, w}-\mathrm{k}_{Q, w}$ (Fig. 18). A relationship $\left(\mathrm{k}_{Q, w}-\mathrm{k}_{q, w}\right)$ determined in the investigations of the composite slab numerical model was applied on the chart with continuous line. Points were next applied on this chart determined in laboratory investigations of 
composite slabs subjected to cyclic and monotonic loads. In the case of cyclic loads, points were applied corresponding to the smallest examined amplitudes $(\mathrm{A}=0.1 \mathrm{~mm})$. In the case of monotonic loads, the points were applied that were recorded in the first phase of loading, when the loading force was approx. $15 \mathrm{kN}$. It was noticed that the points corresponding to the " 0 " condition of the composite slabs are concentrated around the line determined in numerical investigations or are situated just below this line. For this reason, the values $\mathrm{k}_{q, w}$ obtained in numerical calculations and with small loads are associated with the initial stiffness of the joint $\mathrm{k}_{0, q, w}$ (relationship 5.5 and Fig. 16b).

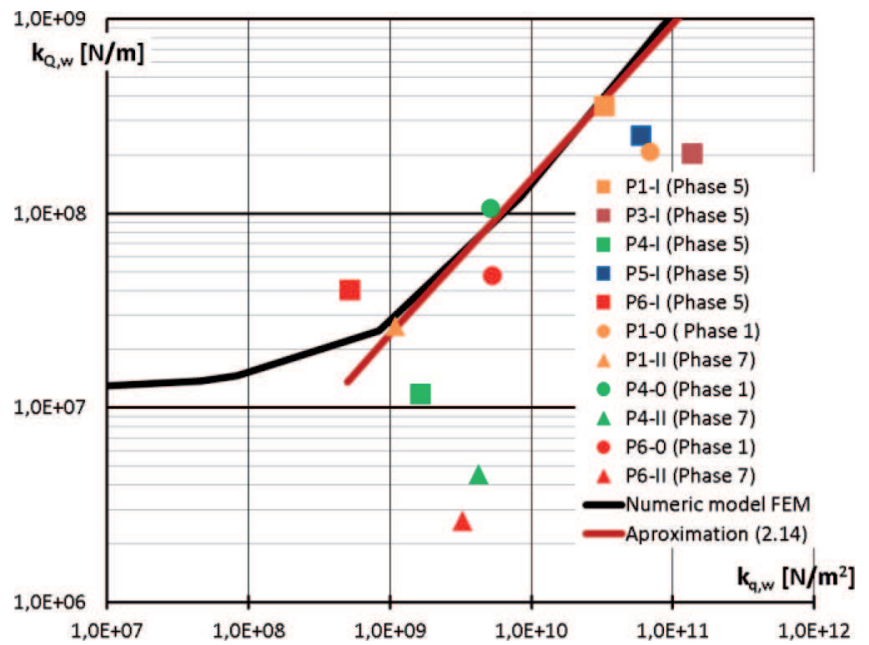

Fig. 18. Relationship between the stiffnesses $\mathrm{k}_{Q, w}$ and $\mathrm{k}_{q, w}$ determined according to the MES numerical model and the relevant stiffnesses approximated on the basis of the investigations.

The impact of the amplitude (A) on the stiffness $\mathrm{k}_{Q . w}$ was analysed by using the finding providing that in the case of the slabs the destruction of which is accompanied by delamination, the stiffness $\mathrm{k}_{Q, w}$ is decreasing along with the amplitude. The relationship $\mathrm{k}_{Q, w}$ from the amplitude was described by introducing initial stiffness $\mathrm{k}_{0, Q, w}$ and by estimating a decrease in stiffness according to the exponential function

$$
k_{Q, w}(A)=k_{0, Q, w} e^{-\lambda A} .
$$

The value $\mathrm{k}_{0, Q, w}$ can be, in the case of slabs with the height of the bottom and top layer of $\mathrm{h}_{d}=0.07 \mathrm{~m}$ and $\mathrm{h}_{g}=0.11 \mathrm{~m}$, within the stiffness range $\mathrm{k}_{q, w}$ between $5 \cdot 10^{8} \mathrm{~N} / \mathrm{m}^{2}$ to $5 \cdot 10^{11} \mathrm{~N} / \mathrm{m}^{2}$, determined according to the following relationship (2.14). The value of the parameter $\lambda$, determined with the method of least squares, changes within a very wide range and depends on the range of amplitudes it is to describe. For instance, the value $\lambda$ in the slab P1 assumes the value from 1800 for the amplitude A for the range of $0.5 \div 2 \mathrm{~mm}$ up to 9100 for amplitudes ranging between 0.1 to $0.5 \mathrm{~mm}$. 
The value would certainly be higher if the data acquired for even smaller amplitudes could be interpolated.

The stiffness model $\mathrm{k}_{Q, w}$ described here will be used in the next publications to describe the non-linear vibrations of composite slabs. The parameter $\lambda$ for the amplitudes smaller than $0.1 \mathrm{~mm}$ can be estimated for the investigated vibrations of composite slabs.

\subsection{ESTIMATION OF ENERGY DISSIPATION PARAMETERS IN A MODEL WITH A SINGLE DEGREE OF FREEDOM}

Energy dissipation in a model of a reinforced-concrete composite slab occurs due to the strains of elastic and frictional elements describing non-conservative forces in the elements modelling a monolithic slab and in the elements describing the influence of the contact layer. The dissipation coefficient $\chi_{Q, w, m}$ is a measure of the quantity of dissipated energy to total energy in the composite slab. If the stiffness $\mathrm{k}_{Q, w}$ is much greater than the stiffness $\mathrm{k}_{Q, m}$, as it happens in case of the investigated slabs, then the relationship (2.7) can be used for estimating the value $\chi_{Q, w}$.

The values of energy dissipation coefficients $\left(\chi_{Q, w, m}\right.$ and $\left.\chi_{Q, m}\right)$ were estimated according to the following relationship (2.4) and (2.6). The surfaces of the hysteresis loops $\psi_{Q, w, m}$ and $\psi_{Q, m}$ necessary for determining the energy dissipation coefficients are taken from Tab. 3 for the "0" condition and Tab. 4 for the "II" condition. The fields $\mathrm{V}_{Q, w, m}$ and $\mathrm{V}_{Q, m}$ were determined as the product of relevant $\Delta \mathrm{Q}$ by $\Delta \mathrm{y}$ provided also in Tab. 3 and Tab. 4. The values of the energy dissipation coefficients obtained for the "0" condition are listed in Tab. 11, and for the "II" condition in Tab. 12.

Table 11

" 0 " slab condition. The estimation of the parameters describing energy absorption by the slab in cyclic loads. The $\chi_{Q, w, m}$ coefficient applies to composite slabs, and the $\chi_{Q, m}$ to a monolithic slab.

\begin{tabular}{|c|c|c|c|c|c|c|c|}
\hline $\begin{array}{c}\text { Loading } \\
\text { phase }\end{array}$ & $\begin{array}{c}\text { Dissipation } \\
\text { coefficient }\end{array}$ & $\mathrm{P} 1$ & $\mathrm{P} 2$ & $\mathrm{P} 3$ & $\mathrm{P} 4$ & $\mathrm{P} 5$ & $\mathrm{P} 6$ \\
\hline \multirow{2}{*}{1} & $\chi_{Q, w, m}\left(\chi_{Q, m}\right)$ & 0.680 & 0.202 & 0.629 & 0.767 & 0.366 & 0.395 \\
\cline { 2 - 8 } & $\chi_{Q, w}$ & 0.478 & & 0.426 & 0.564 & 0.163 & 0.193 \\
\hline \multirow{2}{*}{2} & $\chi_{Q, w, m}\left(\chi_{Q, m}\right)$ & 0.455 & 0.147 & 0.415 & 0.468 & 0.243 & 0.298 \\
\cline { 2 - 8 } & $\chi_{Q, w}$ & 0.308 & & 0.267 & 0.320 & 0.096 & 0.151 \\
\hline \multirow{2}{*}{3} & $\chi_{Q, w, m}\left(\chi_{Q, m}\right)$ & 0.378 & 0.121 & 0.343 & 0.371 & 0.274 & 0.341 \\
\cline { 2 - 8 } & $\chi_{Q, w}$ & 0.257 & & 0.222 & 0.250 & 0.153 & 0.220 \\
\hline \multirow{2}{*}{4} & $\chi_{Q, w, m}\left(\chi_{Q, m}\right)$ & 0.262 & 0.105 & 0.312 & 0.409 & 0.277 & 0.324 \\
\cline { 2 - 8 } & $\chi_{Q, w}$ & 0.158 & & 0.207 & 0.304 & 0.172 & 0.219 \\
\hline
\end{tabular}

The following conclusions can be drawn by analysing the charts illustrating the relationships between the energy dissipation coefficients and the amplitude given in 
"II" slab condition. The estimation of the parameters describing energy absorption by the slab in cyclic loads. The $\chi_{Q, w, m}$ coefficient applies composite slabs, and the $\chi_{Q, m}$ to a monolithic slab.

\begin{tabular}{|c|c|c|c|c|c|c|c|}
\hline $\begin{array}{c}\text { Loading } \\
\text { phase }\end{array}$ & $\begin{array}{c}\text { Dissipation } \\
\text { coefficient }\end{array}$ & $\mathrm{P} 1$ & $\mathrm{P} 2$ & $\mathrm{P} 3$ & $\mathrm{P} 4$ & $\mathrm{P} 5$ & $\mathrm{P} 6$ \\
\hline \multirow{2}{*}{7} & $\chi_{Q, w, m}\left(\chi_{Q, m}\right)$ & 0.359 & 0.210 & 0.559 & 0.164 & 0.107 & 0.131 \\
\cline { 2 - 8 } & $\chi_{Q, w}$ & 0.149 & & 0.349 & 0 & 0 & 0 \\
\hline \multirow{2}{*}{8} & $\chi_{Q, w, m}\left(\chi_{Q, m}\right)$ & 0.431 & 0.160 & 0.434 & 0.232 & 0.208 & 0.231 \\
\cline { 2 - 8 } & $\chi_{Q, w}$ & 0.271 & & 0.274 & 0 & 0.048 & 0.071 \\
\hline \multirow{2}{*}{9} & $\chi_{Q, w, m}\left(\chi_{Q, m}\right)$ & 0.357 & 0.141 & 0.304 & 0.214 & 0.174 & 0.264 \\
\cline { 2 - 8 } & $\chi_{Q, w}$ & 0.215 & & 0.163 & 0.090 & 0.032 & 0.122 \\
\hline \multirow{2}{*}{10} & $\chi_{Q, w, m}\left(\chi_{Q, m}\right)$ & 0.247 & 0.102 & 0.387 & 0.174 & 0.140 & 0.202 \\
\cline { 2 - 8 } & $\chi_{Q, w}$ & 0.145 & & 0.285 & 0.108 & 0.038 & 0.101 \\
\hline
\end{tabular}

Fig. 19. The coefficient $\chi_{Q, w, m}$ is characterised by higher values for the slabs being in the " 0 " condition. and smaller for slabs in the "II" condition. The higher values $\chi_{Q, w, m}$ for the slabs being in the "0" condition exist for smaller amplitudes signifying that its value is falling along with decreasing contact layer stiffness. Meanwhile, in the case of the slabs being in the "II" condition, the value of the coefficient is approximately similar. The monolithic slab dissipation coefficient value is smaller than the composite slabs dissipation coefficient value.

a)

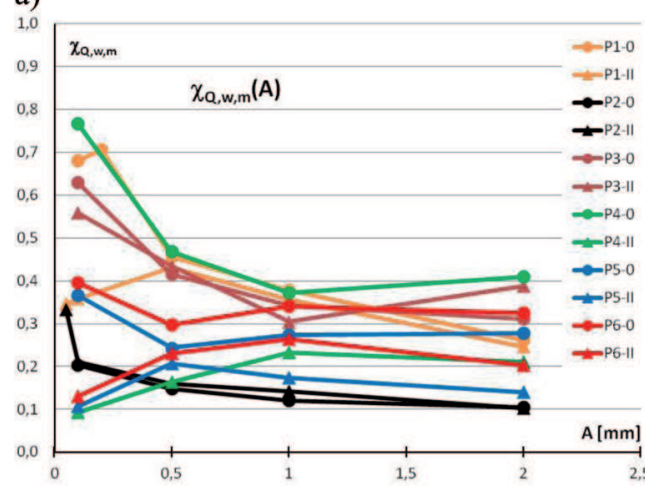

b)

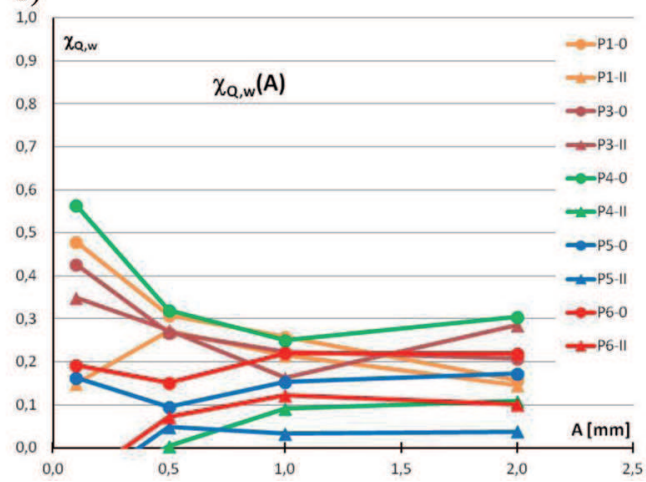

Fig. 19. The energy dissipation coefficients approximated on the basis of the investigations as the values dependent on the amplitude (A) a) coefficient $\chi_{Q, w, m}$ and $\chi_{Q, m}$. b) coefficient $\chi_{Q, w}$. 
The amount of energy dissipated in the slabs being in the "0" condition depends on the contact layer, and, to a smaller extent, the dissipation of energy in the bottom and top layer.

\section{Summary}

The existence of a joint in reinforced-concrete composite slabs is interpreted as the occurrence of a contact layer in a monolithic slab. The article discusses a model of a contact layer [3] and of a composite slab [4] that considers the linear and elastic properties of such layer and internal friction.

The investigations discussed here, referring to slabs with the width of $0.59 \mathrm{~m}$ and height of $0.18 \mathrm{~m}$ and span of $3.00 \mathrm{~m}$, indicate that the stiffness of such layer depends, which is obvious, on the type of the joint and on the loading on the element. The lowest stiffness was experienced for a joint made using a smooth trowelled surface on which cement wash was released. Stiffness of contact layer for such slabs was decreasing ten times from $33 \mathrm{GPa}$ in the initial phase of loading to $3 \mathrm{GPa}$, when a half of the destructive load was applied onto the slab. The greatest stiffness was seen for a joint made using a surface produced as a casting of a smooth mould. Contact layer stiffness for such slabs was decreasing slightly from approx. $125 \mathrm{GPa}$ in the initial phase of loading to $63 \mathrm{GPa}$, when roughly a half of the destructive load was applied. The impact of the vertical reinforcement connecting the bottom and top layer on contact layer stiffness, with $0.04 \%$ of vertical reinforcement, was estimated at between $1 \%$ to $3 \%$.

The slabs featuring higher joint stiffness were characterised by greater energy dissipation. The slabs where the joint was made using a smooth trowelled surface on which cement wash was released, delaminated.

The existence of a joint in actual slabs was interpreted with a model of a composite slab with a single degree of freedom, as the serial connection of monolithic slab stiffness and of stiffness describing the influence of the contact layer. The stiffnesses were approximated in the investigations with the stiffness of the slabs in the point of application of force. The stiffness of a monolithic slab in the point of application of force was approx. $30 \mathrm{GN} / \mathrm{m}$. The stiffness describing the influence of the contact layer was dependent upon loading and was between $26 \mathrm{GN} / \mathrm{m}$ to $208 \mathrm{GN} / \mathrm{m}$ for a smooth trowelled surface on which cement wash was released. The stiffness describing the influence of the contact layer in the slabs that did not delaminate was two times higher than the stiffness of the monolithic slab.

A decrease in contact layer stiffness and in the stiffness describing the influence of the contact layer along with the growing load can be described with an exponential function.

The results of the investigations described indicate that the structure of the contact layer models and composite slab models adopted in the papers [3], [4] is correct. 
Moreover, the findings made constitute a basis for a method being established of assessing the condition of the joint in composite slabs by estimating the parameters of such models.

\section{Aknowledgements}

This paper was sponsored under the POIG.01.01.02-10-106/09-00 program.

\section{REFERENCES}

1. A. Cholewicki, Building structures composed of precast units (in Polish), Wydawnictwa Instytutu Techniki Budowlanej. Warszawa 2001.

2. W. Starosolski, Prefabricated and composite floors. General floors design principles. Construction Review (in Polish), Przegląd Budowlany, 5, 22-24, 2003.

3. K. Gromysz, Longitudinal Shearing Balancing in Joint Surface of Composite Concrete Slabs (in Polish), Inżynieria i Budownictwo, 3, 141-147, 2010.

4. K. Gromysz, Modelling the influence of composite stiffness on energy dissipation in reinforced composite concrete floors, Archives of Civil Engineering, 58, 1, 71-96, 2012.

5. A. Zвісіак, Numerical analysis of dynamic behaviour of eleastoplastic beams. Archives of Civil Engineering, 55, 3, 403-420, 2009.

6. S. GoszcZyŃski, J. ŚLuSARCZYK, Relationship M( $(\kappa)$ for reinforced concrete subjected to changing loads. Archives of Civil Engineering, 55, 1, 65-78, 2009.

7. A. Halicka, A study of the stress - strain condition in the interface and support zones of composite structures with shrinking and expansive concretes (in Polish), Wydawnictwo Politechniki Lubelskiej, Lublin 2007. 